Maria Cecília de Toledo Damasceno

\title{
Prevenção do remodelamento ventricular esquerdo induzido pelo decanoato de nandrolona
}

Tese apresentada à Faculdade de Medicina da Universidade de São Paulo para obtenção do título de Doutor em Ciências.

Área de concentração: Emergências Clínicas

Orientador: Prof. Dr. Antonio Carlos Palandri Chagas

Co-orientador: Dr. Clóvis de Carvalho Frimm

São Paulo

2002 


\section{FICHA CATALOGRÁFICA}

Preparada pela Biblioteca da

Faculdade de Medicina da Universidade de São Paulo

Creprodução autorizada pelo autor

Damasceno, Maria Cecília de Toledo

Prevenção do remodelamento ventricular esquerdo induzido pelo decanoato de nandrolona / Maria Cecília de Toledo Damasceno. -- São Paulo, 2002.

Tese(doutorado)--Faculdade de Medicina da Universidade de São Paulo. Departamento de Clínica Médica.

Área de concentração: Emergências Clínicas.

Orientador: Antonio Carlos Palandri Chagas.

Co-orientador: Clóvis de Carvalho Frimm.

Descritores: 1.DISFUNÇÃO VENTRICULAR ESQUERDA/prevenção \& controle 2.REMODELAÇÃO VENTRICULAR/efeitos de drogas

3.DECANOATOS/efeitos adversos 4.NANDROLONA/efeitos adversos 5.ESTERÓIDES ANABÓLICOS/efeitos adversos 6.ENALAPRILATO/uso terapêutico 7.ESTERÓIDES ANABÓLICOS/farmacologia 
“Quando a saúde está ausente, a sabedoria não pode ser revelada, a arte não pode ser manifesta, a força não pode combater, a prosperidade torna-se inútil e a inteligência não pode ser aplicada".

Escrito por Herophilus, médico de Alexandre, o Grande. 
Aos meus pais,

pela dedicação e abdicação ao longo destes anos. 
AgRadecimentos 
San, a sua parceria e companhia suavizaram a realização deste árduo trabalho.

O meu sincero e reconhecido muito obrigado a todos aqueles que me auxiliaram na realização deste trabalho e aqueles que compreenderam e esperaram pacientemente a minha prolongada ausência. 
SUMÁRIO 


\section{RESUMO}

SUMMARY / ABSTRACT

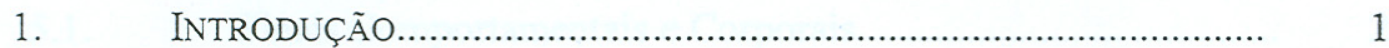

2. REVISÃO DE LITERATURA ......................................................... 5

2.1. Esteróide Anabólico-Androgênico........................................... 6

2.2. Matriz Extracelular................................................................. 11

2.3. Inibidor da Enzima Conversora da Angiotensina.................... 13

3. OBJETIVO

4. MATERIAL E MÉTODOS................................................................. 18

4.1. Modelo Animal...................................................................... 19

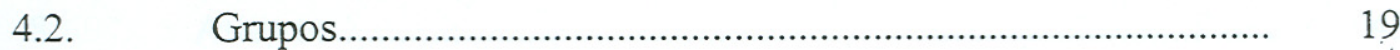

4.2.1. Grupo Nandrolona (ANA) ............................................. 19

4.2.2. Grupo Controle (CON) ..................................................... 20

4.2.3. Grupo Enalaprilato (ENA)................................................ 20

4.2.4. Grupo Nandrolona - Enalaprilato (ANA-ENA)................... 20

4.3. Drogas Utilizadas............................................................. 20

4.4. Procedimentos.................................................................. 21

4.5. Medidas Avaliadas............................................................... 23

4.5.1. Sinais Comportamentais e Corporais................................... 23

4.5.2. Peso $\quad$....................................................................... 23

4.5.3. Peso Seco do Coração............................................................. 24

4.5.4. Peso Úmido do Coração......................................................... 24 
4.5.5. Pressão Arterial Caudal.......................................................... 24

4.5.6. Morfologia e Morfometria.............................................. 25

4.6. Análise Estatística............................................................... 26

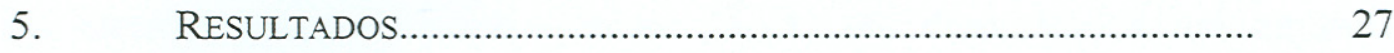

5.1. Sinais Comportamentais e Corporais....................................... 28

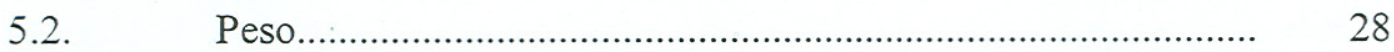

5.3. Peso Seco do Coração............................................................ 29

5.4. Peso Úmido do Coração.......................................................... 29

5.5. Pressão Arterial Caudal.............................................................. 29

5.6. Morfologia e Morfometria...................................................... 29

6. DiSCUSSÃO

7. CONCLUSÃO

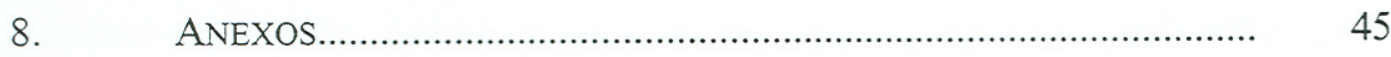

9. REFERÊNCIAS BIBLIOGRÁFICAS.................................................. 60 
RESUMO

= 
DAMASCENO, M. C. T. Prevenção do remodelamento ventricular esquerdo induzido pelo decanoato de nandrolona. São Paulo, 2002. 76 p. Tese (Doutorado) Faculdade de Medicina, Universidade de São Paulo.

Os esteróides anabólico-androgênicos (EAA) são derivados da testosterona que foram desenvolvidos para o tratamento de determinadas condições médicas, como o hipogonadismo e a terapia de reposição androgênica. Embora hoje, as utilizações não médicas feitas por atletas com objetivo de melhorar o desempenho esportivo e por não atletas interessados, em melhorar a força física e a aparência venham chamando mais a atenção, este uso, em geral, caracteriza-se pela administração de doses elevadas de EAA, muito acima das recomendadas terapeuticamente, e desta forma, são inúmeros e em vários órgãos os efeitos indesejados descritos. Os receptores androgênicos miocárdicos regulam a transcripção, a translação e a função enzimática, tendo na testosterona seu mais forte agonista. As alterações secundárias à utilização dos EAA podem ser vistas tanto do ponto de vista patológico como no fisiológico, e são similares àquelas descritas nas fases iniciais da insuficiência cardíaca e da cardiomiopatia. O aparecimento de hipertensão arterial, isquemia miocárdica, morte súbita e o remodelamento ventricular estão associados ao uso de EAA, e estes efeitos têm impacto na mortalidade e morbidade. Os inibidores da enzima conversora da angiotensina (IECA) têm efeitos neurohumorais e hemodinâmicos benéficos na hipertensão arterial e na insuficiência cardíaca, inclusive na regressão, prevenção e aceleração da regressão do remodelamento ventricular esquerdo. Neste estudo, caracterizamos o remodelamento ventricular que ocorre com o uso de um EAA e avaliamos sua relação com a administração concomitante de um IECA. Foram estudados quatro grupos de ratos com 15 animais cada um deles: 1) ratos que receberam injeção semanal de decanoato de nandrolona por três semanas (cinco $\mathrm{mg} / \mathrm{kg}$ de peso, intramuscular); ratos que receberam injeção semanal de óleo de oliva por três semanas como grupo controle (um $\mathrm{ml}$, intramuscular); ratos que receberam injeção semanal de decanoato de nandrolona por três semanas (cinco $\mathrm{mg} / \mathrm{kg}$ de peso, intramuscular) e injeção diária de enalaprilato por três semanas (um $\mathrm{mg} / \mathrm{kg}$ de peso, subcutâneo); e ratos que receberam injeção semanal de óleo de oliva por três semanas (um ml, intramuscular) e injeção diária de enalaprilato por três semanas (um $\mathrm{mg} / \mathrm{kg}$ de peso, subcutâneo). Os animais foram controlados quanto ao peso e tiveram sua pressão arterial mensurada semanalmente. Os pesos úmido e seco de seus corações foram, também quantificados. O remodelamento ventricular foi avaliado através da video-histomorfometria em cortes de coração corados com picrosírius red específico para o colágeno e através de lâminas coradas pela hematoxilina-eosina. Comparando os grupos verificou-se que os animais do grupo decanoato de nandrolona apresentavam maior concentração de colágeno, em relação ao grupo controle $(p<0,05)$ e que o enalaprilato na dose e no tempo utilizados não foi capaz de prevenir o remodelamento ventricular esquerdo $(\mathrm{p}<0,05)$ nos animais que o tiveram administrado concomitantemente ao decanoato de nandrolona. Estes achados mostram que os EAA causam remodelamento ventricular e que o enalaprilato na dose e tempo empregados não demonstrou efeito cardioprotetor e reparador. 
SUMmaRY / ABSTRACT 
DAMASCENO, M. C. T. Prevention of left ventricular remodelling induced by nandrolone decanoate. São Paulo, 2002. 76 p. Ph.D. Thesis - School of Medicine, University of São Paulo.

Anabolic androgenic steroids (AAS) are testosterone by-products that were developed for treating certain medical conditions such as hypogonadism and for androgenic replacement therapies. Today, however, its non-medical uses attract more attention, such as its use by athletes to improve their performance in sports and by non-athletes interested in enhancing their physical strength and appearance. These uses are generally characterized by the administration of high doses of AAS, considerably above those therapeutically recommended, and, in that manner, countless adverse effects have been described in many different organs. Myocardial androgen receptors regulate transcription, translation and enzyme function, and have testosterone as their most powerful agonist. The changes that follow the use of AAS may be seen both from the pathological and from the physiological points of view, and are similar to those described in the initial phases of heart failure and cardiomyopathy. The emergence of hypertension, ischemic heart disease, sudden death, and ventricular remodelling are associated to the use of AAS, and these effects impact mortality and morbidity. Angiotensin converting enzyme inhibitors (ACEI) have beneficial neurohumoral and hemodynamic effects on hypertension and on heart failure, even in the regression, prevention and regression acceleration of left ventricular remodelling. This study describes the ventricular remodelling that takes place with the use of AAS and evaluates its relation with the concomitant administration of ACEI. Four groups, each with 15 rats, were studied: 1) rats that received weekly injections of nandrolone decanoate for three weeks (five $\mathrm{mg} / \mathrm{kg}$ of body weight, intramuscular); 2) rats that received weekly injections of olive oil for three weeks as a control group (one ml, intramuscular); 3) rats that received weekly injections of nandrolone decanoate for three weeks (five $\mathrm{mg} / \mathrm{kg}$ of body weight, intramuscular) and daily injections of enalaprilate for three weeks (one $\mathrm{mg} / \mathrm{kg}$ of body weight, subcutaneous); and 4) rats that received weekly injections of olive oil for three weeks (one ml, intramuscular) and daily injections of enalaprilate for three weeks (one $\mathrm{mg} / \mathrm{kg}$ of body weight, subcutaneous). Animals were weighed to control body weight and had their blood pressure measured weekly. The wet and dry weight of their hearts was determined. Ventricular remodelling was evaluated through videohistomorphometry with heart sections stained with collagen-specific picrosirius red and with hematoxiline-eosine stained slides. The comparison between groups showed that the animals in the nandrolone decanoate group presented greater concentrations of collagen, in contrast with the control group $(p<0.05)$, and that enalaprilate at the dose and for the time used was not capable of preventing left ventricular remodelling $(\mathrm{p}<0.05)$ in the animals that had it administered concomitantly with nandrolone decanoate. These findings show that AAS cause ventricular remodelling and that enalaprilate at the dose and for the time used in this study did not demonstrated cardioprotective and repairing effect. 
1. INTRODUÇÃO 
No Brasil, dificilmente encontramos na atualidade um campo de futebol de várzea, mas a academia de ginástica do bairro está lá. Acanhada ou com grife está cheia de pessoas com um só objetivo: ter um corpo "sarado e marombado", ou seja, musculoso e bem definido.

E isto é fruto de um só fato: a cultura do corpo perfeito. Feiticeira, Florence Griffith Joyner, Alexandre Frota, Ben Johnson, Arnold Schwarzenegger, são estes os corpos que as revistas, jornais e televisão nos mostram todos os dias (Figura 1). A cada ano, milhões de pessoas particularmente os jovens, submetem-se aos mais variados e esdrúxulos meios e métodos para atingir este ideal de corpo, glamouroso pela mídia e tido como o modelo a ser seguido e copiado (Pope, 2000).

Os esteróides anabólico-androgênicos (EAA) são, há muito tempo, utilizados por atletas com o objetivo de melhorar o desempenho esportivo (Sullivan, 1998; Llewellyn, 2000; Robergs, 2002; Taylor, 1982). Em 1939 foi descrita a primeira sugestão de que a testosterona e seus derivados tinham capacidade de aumentar a força muscular e conseqüentemente o desempenho físico; e em 1954 durante o Campeonato Mundial de Levantamento de Peso os russos introduziram os EAA como um método ergogênico (Sullivan, 1998). Estas drogas são amplamente utilizadas em busca do décimo de segundo, do centímetro a mais que, no nosso mundo, significa a diferença entre a vitória e a derrota. Existem, para desilusão do Barão de Coubertin, idealizador dos Jogos Olímpicos Modernos e autor da célebre frase "o importante não é vencer, é competir", relatos na literatura do uso de testículos de touro para aumentar o desempenho físico durante as competições na Grécia Antiga, notadamente, o início dos Jogos Olímpicos (Figura 2). Naquela época, já havia a demonstração do que podemos chamar de super-homens, ou seja, o 
mais veloz, o mais resistente, o que salta mais alto, o que nada mais rápido, enfim o melhor. A mitologia grega muito nos ajuda a comprovar este fato; nela encontramos vários persona gens de musculatura muito bem definida e delineada (Figura 3), parte do ideal de beleza da época (Mavromataki, 1997; Pope, 2000). Na prática esportiva vale praticamente tudo na busca da vitória, do triunfo, da glória, do título de campeão (Figura 4).

Com tudo isto, os EAA tornaram-se rapidamente uma grande tentação para homens e mulheres interessados em melhorar a força física e a aparência. Viraram moda, mais um produto cosmético ou um artifício para pessoas comuns tornarem-se atraentes (Pope, 2000; Parcias 2001; Dickensheets, 2002). Treinamento físico exige muita dedicação e disciplina, horas e anos de treino, descanso adequado, alimentação específica etc. (Robergs, 2002; Bacurau, 2001; Guimarães Neto, 2000; Chinery, 1984; Taylor, 1882). O que há então de ilegal ou de imoral em tomar substâncias químicas que vão me transformar rápida e facilmente em um superhomem, ou uma super-mulher? Nada? Diariamente recebemos a informação de que as pessoas de corpo magro, musculatura definida, tidas como belas, terão mais chances de vencer nesse mundo competitivo, reproduzindo em nossa cotidiana realidade tudo aquilo que vemos nas Olimpíadas e Campeonatos. Por que serei eu o derrotado? Mais uma vez lançam mão de tudo o que estiver disponível para triunfar, vencer. $\mathrm{E}$ o mundo real apresenta uma vantagem em relação às competições, não há exame antidoping. A sociedade não esportiva não tem leis definidas para punir o uso desses artifícios.

Fica uma só pergunta: e a saúde onde está nesta história? Os danos causados pelo uso indiscriminado e abusivo dos EAA são inúmeros e é justamente 
isto que pretendemos demonstrar nesta tese. Até que ponto, na questão da estética e do melhor desempenho físico, os fins justificam os meios? Como já dizia o velho ditado popular: "Por fora bela viola por dentro pão bolorento". 
2. REVISÃO DE LITERATURA 


\section{1. $\quad$ Esteróide Anabólico-Androgênico}

Os esteróides anabólico-androgênicos (EAA) constituem uma classe de medicamentos sintéticos derivados da testosterona, hormônio esteróide natural masculino. Em 1932 a testosterona foi definitivamente estabelecida como o hormônio responsável pelo desenvolvimento das características androgênicas. São

hormônios derivados do colesterol, formando a família dos esteróides da qual, também fazem parte a progesterona, o estradiol, o cortisol e a aldosterona entre outros (Sullivan, 1998; Haupt, 1984).

Os androgênios são responsáveis pela diferenciação, crescimento, desenvolvimento e manutenção do aparelho sexual masculino, das características sexuais secundárias e da fertilidade. Apresentam, também efeitos anabolizantes como crescimento corporal e aumento da massa muscular.

Os EAA foram desenvolvidos com o objetivo de minimizar os efeitos masculinizantes do hormônio natural, maximizando os efeitos sobre a síntese protéica e conseqüentemente sobre o crescimento muscular (Haupt, 1984). Os derivados sintéticos da testosterona podem ser esterificados, alcalinizados ou ter seu anel básico modificado. Cada componente obtido por meio destes processos é diferente estruturalmente da testosterona, e portanto, também serão sua afinidade e eficácia de ligação com os receptores androgênicos (RA) e conseqüentemente seus efeitos anabólico e androgênico. A forma de administração está igualmente relacionada a afinidade e a capacidade de ligação aos RA. Os EAA utilizados de forma parenteral ou oral são rapidamente absorvidos durante sua primeira passagem pelo fígado, são inativados através de reações de redução e conjugação e finalmente 
são excretados na urina (Sullivan, 1998). Ressaltamos que tanto os chamados apenas androgênios como os anabolizantes têm efeitos mistos, variando apenas a proporção androgênico anabólica em cada apresentação; assim a forma mais correta de denominá-los é EAA. A testosterona tida como referência, apresenta uma proporção anabólica androgênica de 1:1. O decanoato de nandrolona, utilizado neste trabalho, tem uma proporção de 8:1. Os EAA são utilizados para o tratamento de algumas doenças, como a deficiência de testosterona, algumas formas de anemia e para osteoporose, sendo seu uso não médico o que tem chamado mais a atenção. Estimase que de 4 a $11 \%$ dos homens e 0.5 a $2.5 \%$ das mulheres americanas tenham feito uso destas drogas. Neste momento, no Brasil não existem dados precisos sobre a incidência ou prevalência do uso de EAA.

A toxicidade dos EAA pode ser atribuída em grande parte a dosagem e a técnica de administração (Sullivan, 1998; Llewellyn, 2000). Na prática os usuários utilizam doses de 10 a 100 vezes maiores que as terapêuticas e recomendadas em bula dos respectivos produtos (Figuras 5). Existem relatos de utilização de doses até $350 \%$ maior que as preconizadas e de associação de várias destas drogas (Guimarães Neto, 2000; Sullivan, 1998).

O mecanismo de ação da testosterona ainda não está totalmente elucidado. Como molécula livre no plasma ela interage com os receptores androgênicos intracelulares encontrados em vários órgãos; uma vez feita à ligação, o complexo formado dentro do núcleo celular irá estimular a transcripção de genes específicos (Sullivan, 1998; Micromedex, 2001). A forma de atuação dos EAA é semelhante ao da testosterona; eles ligam-se ao RA gerando uma alteração 
conformacional que, por sua vez expõe determinados segmentos do DNA, estimulando a transcripção de genes específicos (Figura 6).

No caso específico da musculatura esquelética o estímulo será para realizar síntese protéica, ou seja, crescimento muscular. Este efeito ocorre depois que a nandrolona passa a $5 \alpha$-dihidro-nandrolona através da $5 \alpha$-redução, ligando-se aos RA. Aparentemente os RA são idênticos em todos os tipos de células e as manifestações ao estímulo dos EAA são resultantes da composição entre: o número total de receptores, a proporção entre o número de receptores nos tecidos extragenitais comparados aos genitais, a atividade relativa da enzima $5 \alpha$-redutase presente nestes locais, a atividade concomitante dos glicocorticóides e a quantidade de receptores que são expressos nas células (Sullivan, 1998;Wilson, 1988). Sabemos, também que cada EAA têm uma afinidade e uma eficácia de ligação diferente com os RA, relacionada à estrutura química da molécula (Sullivan, 1998).

No sistema cardiovascular humano são encontrados receptores androgênicos altamente específicos, saturáveis e de alta afinidade (Rockhold, 1993). Os RA são encontrados em ventrículo, átrio, aorta e vasos periféricos (Mcgill, 1981). Quanto aos receptores de glicocorticóides sabemos que, também eles interagem com os EAA e que em condições fisiológicas os glicocorticóides exercem papel catabólico sobre a musculatura esquelética, que pode ser inibida pela concentração suprafisiológica que os EAA determinam (Snochowski, 1981).

As alterações morfológicas diretas que os EAA causam no miocárdio são bem documentadas e serão discutidas a seguir (Campbell, 1993; Appel, 1983; Sullivan, 1998). As alterações histológicas são similares àquelas encontradas nas fases iniciais da insuficiência ventricular esquerda (Appel, 1993; Behrendt, 1977). Em 1977, 
Behrendt demonstrou que a exposição de ratos a metandrostenolona provocava um aumento do ventrículo esquerdo, com mitocôndrias de aparência arredondada e membrana de aspecto defeituoso. Alterações na matriz e crista foram também descritas (Behrendt, 1977). Em porcos esta mesma droga induz a destruição mitocondrial e aumento da relação mitocôndria: miofibrilas (Behrendt, 1977). Através da microscopia eletrônica observou-se destruição de sarcolemas, desaparecimento regional de ribossomos e polissomos, assim como, o afinamento das bandas I e displasia intrafibrilar (Appel, 1983). Estas alterações no retículo sarcoplasmático parecem ser ATPase dependente.

O espaço extracelular no miocárdio de ratos tratados com metandrostenolona é ocupado com feixes de fibrilas colágenas e as células têm aparência de estarem separadas, como visto nas fases iniciais da fibrose da insuficiência cardíaca congestiva (Sullivan, 1998). Em cães, sabe-se que os EAA causam aumento do conteúdo hidroxiprolina estimulando a redistribuição transmural de colágeno (Karhunen, 1988).

$\mathrm{Na}$ função enzimática dos miócitos os EAA parecem ter efeito variável. Ele seria dependente do controle que os androgênios exercem nos receptores cardíacos, como já discutidos anteriormente (Sullivan, 1998). Koenig, em 1982, demonstrou que a testosterona pode induzir poliaminas de miócitos ventriculares esquerdos de ratos a ativar o fluxo intracelular de cálcio e o transporte das membranas; neste mesmo trabalho foi descrito que, os andrógenos endógenos regularam o crescimento e parte da atividade enzimática miocítica (Koenig, 1982). Legnsfeld, em 1988, demonstrou que a testosterona favorece a expressão da isoenzima $\alpha$-miosina de cadeia pesada independente dos estímulos hemodinâmicos 
existentes; lembrando que determinadas condições hemodinâmicas levam ao aparecimento de hipertrofia cardíaca induzidas pela $\beta$ - miosina de cadeia pesada (Legnsfeld, 1988, Baker, 1978).

Trifunovic, em 1995, publicou um interessante trabalho sobre a complacência ventricular esquerda sob ação do decanoato de nandrolona, onde ele descreve a ocorrência de redução regional da complacência miocárdica sinalizando mudanças na geometria ventricular. Ele igualmente sugere que ocorra alteração na função sistólica do ventrículo esquerdo (Trifunovic, 1995).

Estudos recentes de Welder e Merchert (Welder, 1995; Melchert, 1992) mostraram que os EAA causam toxicidade direta no miocárdio, dependente tanto, da dosagem como da duração do uso. Eles sugerem que a perda da viabilidade celular é resultante, em parte, das alterações de concentração iônicas após a perda da integridade da membrana plasmática, e da inabilidade de sintetização de fostatos de alta energia. Esta lesão direta causaria necrose tecidual e conseqüentemente áreas fibróticas, locais estes de predisposição para o aparecimento de arritmias cardíacas fatais (Melchert, 1995).

Anteriormente, já relatamos o fato da hipertrofia da musculatura esquelética secundária ao uso de EAA ser em parte atribuída à inibição da atividade dos glicocorticóides (Sullivan, 1998). No coração, no entanto, seu mecanismo é um pouco diferente, pois tanto os andrógenos, como os glicocorticóides têm funções anabólicas. A administração de glicocorticóides causa crescimento do miocárdio através da inibição da degradação protéica. E por sua vez, a realização de determinadas atividades físicas pode causar inicialmente hipertrofia miocárdica, sendo possível a demonstração do aumento de receptores de glicocorticóides na 
superfície cardíaca (Sullivan, 1998). Após a realização de treinamentos físicos que induzem o aparecimento de hipertrofia miocárdica, demonstrou-se aumento da concentração de receptores de glicocorticóides na superfície, fato este que, claramente contribui para o processo adaptativo que se segue (Sullivan, 1998). Cabe ressaltar que a atividade física pode elevar a quantidade de colágeno miocárdico na proporção direta do grau de hipertrofia desenvolvida pelo esforço físico, mas sempre mantendo a proporção entre proteínas colágenas e não colágenas (Sullivan 1998).

Entre outras alterações cardíacas desencadeadas pelos EAA podemos citar: a isquemia miocárdica, aterosclerose, aume nto do LDL colesterol, diminuição do HDL colesterol, vasoespasmo e trombose supostamente por alteração de reatividade vascular (Mevis, 1996; Green, 1993; Ferrer, 1994). Eles, também aumentam a eritropoiese e estimulam o sistema nervoso central a liberar gonadotrofinas, alteram a biomecânica das articulações, aumentam a osteogênese e a inibição da reabsorção óssea e em homens suprimem a função testicular (Llewellyn, 2000).

\section{2.}

\section{A Matriz Extracelular}

A matriz extracelular é constituída de colágeno fibrilar, seu principal elemento elástico (Villareal, 1998; Borg, 1995). Ele é sintetizado na forma de prócolágeno contendo um pró-peptídeo amino e carboxiterminal. Após o pró-colágeno ser secretado no espaço extracelular, os pró-peptídeos são removidos por proteinases específicas permitindo assim a incorporação na fibra em crescimento (Díez, 1997). O colágeno tipo I é responsável pela estruturação do interstício e espaço periventricular, mantendo a necessária estrutura para a contratilidade muscular. Seus 
acúmulos desproporcionais que envolvem síntese e degradação, produzem alterações no arcabouço do coração, com fibrose miocárdica e hipertrofia ventricular (Matsubara, 1995). A fibrose é definida não apenas como aumento da concentração da matriz colágena no interstício, mas também como alteração no tipo de colágeno e na sua organização. E esta fibrose secundária ao remodelamento mal adaptado na matriz extracelular pode causar disfunção miocárdica.

Vários estudos confirmam o envolvimento do sistema reninaangiotensina-aldosterona (SRAA) na fibrose tissular. A atividade da angiotensina II (Ang II) é mediada por receptores de membrana AT1 e AT2. A aldosterona (Aldo), um potente mineralocorticóide, é por sua vez produzido nas adrenais por estímulo da Ang II, estando sua produção tecidual ainda sob investigação. Estudos em cultura de células demonstraram estímulo importante da Ang II e da Aldo na produção de colágeno (Brilla, 1994; Brilla 1997; Wolf, 1992) e o aumento crônico dos níveis circulantes de Ang II ou Aldo parecem estimular a fibrose miocárdica (Sun, 1997, Sun, 1994).

Hoje, sabe-se que também as endotelinas (ET), peptídeos com grande potência vasoconstrictora, têm participação na remodelação ventricular. Estudos com culturas de células permitiram a identificação da participação das endotelinas I e II na produção de colágeno. A relação do SRAA e das ET é complexa, sabemos que as ET são capazes de estimular a produção de Ang II, tanto por estímulo direto, como por aumento da atividade da enzima de conversão da angiotensina. Um ponto em comum existente entre os hormônios do SRAA e as ET é a elevação dos níveis citoplasmáticos do cálcio. Tanto a Ang II, como a Aldo e as ET promovem, por diversos mecanismos, níveis elevados de cálcio intracelular. Este íon atua como um 
dos mensageiros no estímulo à síntese de colágeno. Brock, em 1985, demonstrou em cultura de células um aumento de fosfolipase C, estimuladas por Ang II (Brock, 1985). A fosfolipase C é responsável pelo aumento do trifostato de inositol, que por sua vez, aumenta a transferência de cálcio das reservas do retículo sarcoplasmático para o citoplasma (Alexander, 1985). Fibroblastos e miofibroblastos são as principais células do miocárdio responsáveis pelo acúmulo de colágeno e conseqüentemente da fibrose miocárdica (Cleutjens, 1995). Sabemos que, os miofibroblastos possuem receptores de Ang II, ET e Aldo (Guarda, 1993), portanto a interação destes hormônios, associada à elevação de cálcio citoplasmático, forma um complexo mecanismo com importante implicação no desenvolvimento da fibrose miocárdica.

\subsection{Inibidores da Enzima Conversora da Angiotensina}

O desenvolvimento dos inibidores da enzima conversora da angiotensina (IECA) iniciou-se há mais de trinta anos com a descoberta do chamado fator potencializador da bradicinina, como foi chamado na época pelos pesquisadores brasileiros Sérgio H. Ferreira e Maurício Rocha e Silva. Esse fator era uma mistura de peptídeos que inibia a atividade da cininase II, prevenindo a degradação da bradicinina (Ferreira, 1965). Posteriormente, verificou-se que apresentava potente ação inibitória sobre a enzima conversora de angiotensina (ECA), e desde então foram desenvolvidos vários compostos. Essas drogas antagonizam os efeitos da angiotensina II, tanto vasoconstritores, como estimulantes da síntese de aldosterona. Simultaneamente inibem a degradação da bradicinina e aumentam os níveis de prostaglandinas vasodilatadoras. Não causam taquicardia, pois não há indução de atividade simpática reflexa, provavelmente por atuação em baroreceptores. Causam 
também, venodilatação e diminuem a pós-carga, sem comprometer o débito cardíaco, em parte dos casos aumentado-o (Jackson, 1996).

Em conseqüência, os inibidores da ECA exercem efeitos neurohumorais e hemodinâmicos benéficos na hipertensão arterial e na insuficiência cardíaca, inclusive na regressão, prevenção e aceleração da regressão da hipertrofia ventricular esquerda (Dzau, 1988). O estímulo à produção exacerbada de determinados hormônios ocorre, a princípio, como mecanismo compensatório na tentativa de evitar um colapso circulatório. Porém, o aumento do nível circulante e local destas substâncias pode desencadear alterações estruturais e geométricas no coração. Esta alteração estrutural seria representada, em parte, pelo acúmulo desapropriado de colágeno nos diferentes compartimentos do miocárdio promovendo desorganização da morfologia do coração (Jalil, 1989; Crawford, 1994; Coker, 1998).

Nos vasos o uso crônico dos IECA previne, reduz ou mesmo reverte à hipertrofia e a fibrose da parede vascular. Na aorta são descritos estudos que comprovaram a redução da densidade do colágeno (Levy, 1988). Nas pequenas artérias e arteríolas, a administração crônica dos IECA também resulta em diminuição da espessura da média e da relação parede/lúmen (Cruishank, 1982). Os IECA têm propriedade de reduzir a hipertrofia ventricular esquerda em hipertensos, eles diminuem a massa do ventrículo esquerdo predominantemente pela redução da espessura da parede posterior e do septo interventricular, e em menor grau pelo encurtamento do diâmetro ventricular (Cruishank, 1992; Dählof, 1992). Este efeito seria resultado da modulação do sistema renina-angiotensina tecidual e do sistema nervoso simpático; e da redução na pós-carga nas grandes artérias. 
Os mecanismos na insuficiência cardíaca são complexos. Ocorre o bloqueio da ativação do sistema renina-angiotensina, vasodilatação arteriolar e venosa e menor retenção de sódio e água. Há também aumento de prostaglandinas e inibição da degradação da bradicinina, reduzindo a pré e a pós-carga (Borek, 1991; Swartz, 1987).

Tendo como base estas informações, procuramos elaborar um projeto experimental onde a utilização de um IECA teria papel preventivo no remodelamento ventricular induzido por um EAA. 
3. OBJETIVO

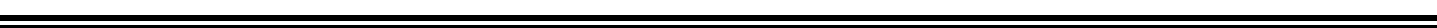


O objetivo deste estudo foi in vivo:

Avaliar o comportamento da musculatura ventricular sob ação do decanoato de nandrolona, através da video-histomorfometria.

Avaliar a influência do maleato de enalapril no remodelamento ventricular esquerdo, na presença do tratamento concomitante com decanoato de nandrolona. 
4. Material e Métodos

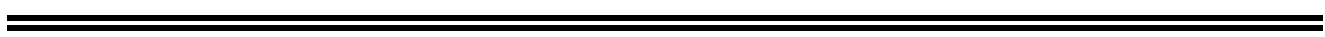


Este estudo foi aprovado na Comissão de Ética para Análise de Projetos de Pesquisa (CAPPesq) da Diretoria Clínica do Hospital das Clínicas e da Faculdade de Medicina da Universidade de São Paulo em 29 de abril de 1999. Sua realização deu-se no Laboratório de Investigação Médica (L.I.M. 51) da Disciplina de Emergências Clínicas da Faculdade de Medicina da Universidade de São Paulo.

O tratamento dos animais e o experimento foram realizados seguindo as orientações estabelecidas por esta Comissão.

O estudo é experimental com desenho em quatro grupos, incluindo um controle.

\subsection{Modelo Animal}

Foram utilizados 60 ratos (Rattus norvegicus albinus, Rodentia, Mammalia), da linhagem FMUSP-Wistar, machos, com peso entre 196 e 310 gramas, provenientes do Biotério Central da FMUSP. Cada um dos grupos apresentava de forma similar 15 ratos de características comparáveis com objetivo de gerar uma informação confiável.

\subsection{Grupos}

\subsubsection{Grupo Nandrolona (ANA)}

Ratos submetidos uma vez por semana, durante três semanas consecutivas à injeção intramuscular de decanoato de nandrolona (DecaDurabolin®- Akzo Nobel Ltda - Divisão Organon) de cinco mg/kg de peso (Behrendt, 1977). 


\subsubsection{Grupo Controle $(\mathrm{CON})$}

Ratos submetidos uma vez por semana, durante três semanas consecutivas à injeção intramuscular de suspensão de óleo de oliva de um ml.

Optou-se por utilizar este veículo, visto a droga a ser comparada, ser uma solução igualmente oleosa. Desta maneira o estresse desencadeado pelas injeções seriam comparáveis.

\subsubsection{Grupo Enalaprilato (ENA)}

Ratos submetidos uma vez por semana, durante três semanas consecutivas à injeção intramuscular de suspensão de óleo de oliva de um ml, e diariamente durante este mesmo período à injeção subcutânea de enalaprilato (Renitec® - Merck Sharp \& Dohme Farmacêutica e Veterinária) de um mg/kg de peso.

\subsubsection{Grupo Nandrolona - Enalaprilato (ANA-ENA)}

Ratos submetidos uma vez por semana, durante três semanas consecutivas à injeção intramuscular de decanoato de nandrolona de cinco mg/kg de peso e diariamente, neste mesmo período à injeção subcutânea de enalaprilato de um $\mathrm{mg} / \mathrm{kg}$ de peso.

\subsection{Drogas Utilizadas}

O decanoato de nandrolona é um EAA, de uso injetável. Ele é gradualmente liberado do depósito intramuscular e subseqüentemente hidrolisado 
pelas estearases do plasma em nandrolona. O pico sérico ocorre entre oito e vinte e quatro horas após sua aplicação. O metabolismo é hepático e a excreção renal. A dose utilizada de cinco $\mathrm{mg} / \mathrm{kg}$ de peso por semana é considerada elevada (Behrendt, 1977; Trifunovic, 1995). A monografia do produto recomenda a utilização de vinte e cinco a cinqüenta miligramas a cada três semanas para um indivíduo adulto de aproximadamente setenta quilos de peso. Esta dose elevada foi baseada em prática rotineira de atletas e não atletas interessados em ter um desempenho físico melhorado (Guimarães Neto, 2000; Llewellyn, 2001).

O maleato de enalapril é um dos inibidores da enzima conversora da angiotensina (IECA) e têm diversas ações conhecidas, como bloqueio simpático, ação sobre a bradicinina, angiotensina, prostaglandinas, além de atuação nos receptores de membrana adrenérgicos, da angiotensina II (AT1 e AT2) e nos canais iônicos de cálcio (Moolenar, 1987; Cooper, 1987; Monografia do Produto, 1998). Os IECA ao participarem destes processos demonstram papel importante e conjunto sob a ação humoral e, sobretudo tissular, em relação à regressão, prevenção e a aceleração da regressão da hipertrofia ventricular esquerda (Dzau, 1988). A dose empregada foi de um $\mathrm{mg} / \mathrm{kg}$ via subcutânea diariamente.

\subsubsection{Procedimentos}

Os animais de cada um dos grupos foram transportados para o Biotério que serve o Laboratório de Investigação Médica da Disciplina de Emergências Clínicas (L.I.M. 51) e confinados em gaiolas plásticas, com tampo de metal gradeado, no total de cinco animais por gaiola. Foram pesados em balança digital (Marte LCV3. 0 - Brasil) e mantidos em temperatura constante de vinte e dois 
graus Celsius, controlada por termômetro e ar condicionado. O regime de iluminação foi efetuado com lâmpadas fluorescentes, modelo luz do dia (quarenta watts), com ciclo circadiano, ou seja, doze horas no escuro e doze horas na luz. Como alimentação receberam ração básica e água ad libidum. Após o período de sete dias de adaptação os animais foram pesados novamente em balança digital (Marte LCV3. 0 - Brasil) e identificados com tinta em partes diferentes do corpo. No dia na injeção semanal de decanoato de nandrolona ou óleo de oliva os animais tinham novamente seus pesos medidos (figuras 7 e 8 ).

Ao final do experimento, os ratos foram anestesiados pelo éter etílico, posicionados em decúbito dorsal, e realizada toracotomia mediana para retirada do coração. O sacrifício foi realizado através de injeção intracardíaca de cloreto de potássio a $10 \%$ que promove a parada cardíaca em diástole. Foram, também retirados fragmentos do lobo direito do fígado e do músculo gastrocnêmico direito.

Em sete ratos de cada grupo, os corações foram pesados em balança eletrônica analítica (Mettler-Toledo AB 204 - Switzerland) e, em seguida, colocados em estufa de esterilização (Quimis 317 B112 - Brasil) a cem graus Celsius por vinte e quatro horas e realizada nova pesagem, para determinação do peso seco do coração.

O coração foi dividido em três partes: a base (incluindo vasos da base, átrios e parte dos ventrículos) e a ponta foram congelados, instantaneamente, em isopentano com gelo seco e mantidos a $-75^{\circ} \mathrm{C}$, após terem sido preenchidas as cavidades com tissue freeze medium. A porção média do coração foi mantida em formol, assim como, os fragmentos de fígado e do músculo gastrocnêmico. Foram, também retirados da porção média, fragmentos do ventrículo esquerdo, destinados à microscopia eletrônica, após serem reduzidos a peças cúbicas de um mm de aresta e 
colocados em solução fixadora gelada de glutaraldeído (2\%) em tampão fostato $(0,1$ M) e $\mathrm{pH} 7,2$.

Os fragmentos de coração para realização de imunohistoquímica, autorradiografia e microscopia eletrônica, assim como, fragmentos de fígado e do músculo gastrocnêmico foram guardados para análise posterior.

A porção do coração mantida em formol foi preparada em parafina e então realizados cortes transversais seriados com seis $\mu \mathrm{m}$ de espessura, englobando ambos os ventrículos, com montagem de lâminas para coloração. Os tecidos foram corados com picrosírius red para identificação do colágeno e hematoxilina-eosina (HE) para análise histológica (SUN, 1993). Para posteriores análises foram, também coradas lâminas para elastina e Ag-nor (Nucleonar Organizer Regions).

\subsection{Medidas Avaliadas}

\subsubsection{Sinais Comportamentais e Corporais}

Semanalmente os ratos foram observados quanto a eventuais mudanças comportamentais e corporais que pudessem ocorrer entre os diversos grupos. Elas foram quantificadas através de um sistema de pontuação de presença (+) e ausência $(-)$. Estas observações foram feitas por um observador que não tinha conhecimento prévio dos grupos.

\subsection{2. $\quad$ Peso}

Os animais tiveram seu peso acompanhado por mensuração realizada semanalmente em balança digital (Marte LCV3. 0 - Brasil). No total foram realizadas cinco medidas, na entrada dos animais no Biotério utilizado pela Disciplina de 
Emergências Clínicas, na primeira, segunda e terceiras semanas de injeção dos medicamentos e no dia do sacrifício dos animais.

\subsubsection{Peso Úmido do Coração}

Sete ratos de cada grupo tiveram seus corações pesados em balança eletrônica analítica (Mettler-Toledo AB 204 - Switzerland) para determinação do peso úmido do coração.

\subsubsection{Peso Seco do Coração}

Sete ratos de cada grupo tiveram seus corações pesados em balança eletrônica analítica (Mettler-Toledo AB 204 - Switzerland) e, em seguida, colocados em estufa de esterilização (Quimis 317 B112 - Brasil) a cem graus Celsius por vinte e quatro horas e realizada nova pesagem, para determinação do peso seco do coração.

\subsubsection{Pressão Arterial}

Uma vez por semana foram realizadas medidas da pressão arterial dos animais, feita na cauda do animal (Pressure Meter LE 5001 Letica S.A. Scientific Instruments - Estados Unidos). Conforme orientações do manual do equipamento e literatura relacionada (Bonãg, 1973), os ratos foram acostumados à realização da medida, sendo mantidos em ambiente tranqüilo e silencioso, e expostos à temperatura de trinta e cinco graus Celsius por aproximadamente vinte minutos com objetivo de melhorar a vasodilatação periférica e conseqüentemente a acurácia da medida. A cauda dos animais foi limpa previamente com água, também com o objetivo de melhor obtenção das medidas da pressão arterial. Uma vez feita à 
calibração do aparelho, foram realizadas três medidas em cada rato, com intervalos de aproximadamente dois minutos.

Após a obtenção destas três medidas, foi feita a média padrão dos valores de pressão arterial sistólica e diastólica.

\subsubsection{Morfologia e Morfometria}

Foram feitos cortes seriados em parafina de seis $\mu \mathrm{m}$ e corados com picrosírius red, específico para o colágeno. As frações do volume de colágeno intersticial (FVCI) do ventrículo esquerdo foram então determinadas. A quantificação foi feita através de vídeo histomorfometria utilizando-se um sistema de análise de imagens (Image Processing and Analysis System - Leica Imaging Systems Ltd - Inglaterra). A quantificação da FVCI foi determinada calculando-se a porcentagem de área de colágeno sobre área total de miocárdio, analisando-se cortes seriados e múltiplos campos (10 campos/corte, magnificação de vinte vezes). As lâminas coradas com hematoxilina-eosina (HE) foram submetidas à quantificação miocítica utilizando-se um retículo de medição acoplado ao microscópio de luz com ampliação de 40x (Carl Zeiss, Alemanha).

O procedimento de análise das lâminas foi feito por um indivíduo analisador que não tinha conhecimento da identificação dos respectivos grupos. 


\subsection{Análise Estatística}

A análise dos dados compreendeu os 60 animais, divididos nos quatro grupos (ANA,CON, ENA e ANA-ENA).

Foi aplicado teste de variância de Anova Kruskal Wallis com a finalidade de comparar os quatro grupos (Siegel, 1975; Arango, 2001). Nos casos em que o teste identificou diferença estatisticamente significante, complementourse com análise de comparações múltiplas, de forma a melhor explorar a diferença (Hollander e Wolfe, 1973). Todos os resultados foram interpretados utilizando-se o nível de significância de $5 \%$ e intervalo de confiança de $95 \%$. Os cálculos foram feitos por meio do sistema computacional Statistical Analysis System (Statistix for Windows 2.0 Analytical Software 1988 - Estados Unidos). Os resultados estão expressos como valor médio, mediana e desvio padrão. 
5. Resultados

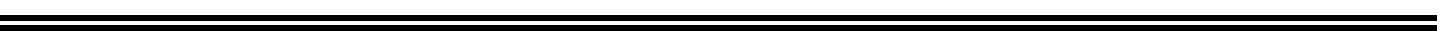


Inicialmente gostaríamos de destacar que todos os ratos completaram o protocolo. A única intercorrência ocorreu no grupo ANA, na terceira semana do experimento, quando um dos animais ao morder a luva utilizada para segurá-lo durante a aplicação do medicamento, apresentou sangramento de pequena monta nos dentes frontais.

Após a abertura da cavidade torácica e abdominal não foram observadas quaisquer alterações macroscópicas nos órgãos estudados.

\subsection{Sinais Comportamentais e Corporais}

A partir da segunda semana de utilização de decanoato de nandrolona foram observadas as seguintes reações nos animais dos grupos ANA e ANA-ENA: maior agressividade, agitação e presença de pêlos eriçados. O pêlo dos animais destes grupos tornou-se opaco e amarelado. Nos grupos CON e ENA não houve mudança aparente do comportamento nem na aparência do pêlo quando comparado as semanas iniciais do experimento. A intensidade das reações para cada animal estudado está apresentada no quadro 1.

\subsection{Peso}

Os valores obtidos na quarta semana de realização do experimento estão descritos na tabela 1. Houve diferença estatisticamente significante na mensuração do peso entre grupos estudados neste período de tempo. Os animais que receberam nandrolona apresentam peso corpóreo maior que os dos grupos $\mathrm{CON}$ e ENA. 


\subsection{Peso Seco do Coração}

Os valores obtidos estão descritos na tabela 2. Não foi encontrada diferença estatisticamente significante na mensuração do peso seco dos corações nos grupos estudados.

\section{4. $\quad$ Peso Úmido do Coração}

Os valores obtidos estão descritos na tabela 3. Não foi encontrada diferença estatisticamente significante na mensuração do peso seco dos corações nos grupos estudados.

\subsection{Pressão Arterial Caudal}

Não foi encontrada diferença estatisticamente significante na mensuração da pressão arterial caudal entre os grupos estudados ao longo das semanas de realização do experimento. Em nenhum momento foi evidenciada hipertensão arterial nos ratos dos grupos ANA, ENA, ANA-ENA e ENA. Os resultados podem ser visualizados na tabela 4 .

\subsection{Morfologia e Morfometria}

Analisando os tecidos por meio de video-histomorfometria, como descrito anteriormente, observou-se:

$>$ Aumento da quantidade de colágeno no interstício ventricular esquerdo nos animais dos grupos que receberam decanoato de nandrolona (ANA) e que receberam decanoato de nandrolona e enalaprilato concomitantemente (ANA-ENA) quando 
comparados aos dos grupos controle $(\mathrm{CON})$ que receberam injeção de óleo de oliva e do grupo que recebeu óleo de oliva e enalaprilato simultaneamente (ENA), (Figuras 9, 10, 11, 12, 13 e 14). Este aumento representou diferença significativa na análise estatística $(\mathrm{p}<0.05)$. As medidas da fração do volume de colágeno intersticial (FVCI) podem ser vistas na tabela 5. Não foi encontrada diferença estatisticamente significante na análise de quantificação miocítica realizada entre os quatro grupos estudados ao longo das semanas de experimento. Os resultados podem ser vistos na tabela 6 . 
6. DisCuSSÃo 
No presente trabalho, estudou-se a ação do enalaprilato na prevenção do remodelamento ventricular esquerdo induzido pelo decanoato de nandrolona em ratos. A revisão sistematizada da literatura não evidenciou publicações com os objetivos e metodologias superponíveis a este estudo.

Com relação aos animais utilizados, cuidou-se para que houvesse um período de adaptação às condições do biotério em que foi realizado o estudo para minimizar o estresse dos mesmos, permitindo uma melhor aferição da pressão arterial caudal e de eventuais mudanças comportamentais. A manutenção de níveis normais da pressão arterial durante todo o estudo foi fundamental no intuito de afastar eventuais distorções que a hipertensão arterial poderia provocar no mesmo (Sullivan, 1998).

O rato foi o animal escolhido para este experimento, por ser alvo de inúmeros outros estudos com as drogas empregadas, permitindo uma melhor análise e comparação de resultados.

Inicialmente, observamos algumas alterações comportamentais nos ratos dos grupos que receberam nandrolona; os animais estiveram nitidamente mais agitados e agressivos quando comparados aos dos grupos controle e enalaprilato, chegando um deles, inclusive a ferir-se ao morder a luva utilizada para aplicar o medicamento. Embora subjetiva, esta mudança comportamental pode ser observada a partir da segunda semana de uso do decanoato de nandrolona (Yu-Yahiro, 1989). Os EAA são conhecidos por seus efeitos psiquiátricos, onde podem causar quadros maniformes, psicóticos e depressivos, particularmente quando doses elevadas são empregadas (Council on Scientific Affairs, 1990). Muitos também são os relatos na 
literatura de atos violentos e crimes cometidos por indivíduos que não apresentavam qualquer traço agressivo antes da utilização de EAA (Conacher, 1989; Pope, 1990; Dalby, 1992). Os relatos subjetivos de aumento de entusiasmo, agressividade e irritabilidade durante seu uso são corriqueiros entre os usuários e, em geral, aparecem após as primeiras semanas das aplicações (Llewellyn, 2000; Guimarães Neto, 2000).

Outra alteração observada foi o aparecimento de pêlos de coloração amarelada e bastante opaca nos animais dos grupos ANA e ANA-ENA. Esta observação foi descrita em outros estudos que utilizaram EAA (Yu-Yahiro, 1989). Os animais dos grupos CON e ENA não apresentaram qualquer mudança em relação ao pêlo ao longo das semanas de estudo. Não se sabe até o momento a razão desta alteração; em humanos são descritos casos de alopecia durante e após o uso de EAA. Com relação ao peso evidenciou diferença significativa entre os grupos estudados. Ao final do experimento, os animais dos grupos ANA e ANAENA estavam mais pesados que os do grupo CON e ENA. Alguns EAA podem causar retenção hídrica e de sal, sendo este efeito colateral, geralmente, dose, droga e tempo dependente. A conversão aumentada de estrógeno, que algumas destas drogas causam, seria responsável pelo aparecimento deste efeito colateral. O decanoato de nandrolona é tido como uma droga intermediária neste quesito (Llewellyn, 2000; Monografia do produto, 1992). Yu-Yahiro mostrou que, esta desproporção entre dosagem e peso é marcante a partir da terceira semana de uso da nandrolona (YuYahiro, 1989). Estes dados são compatíveis com os encontrados neste nosso trabalho. 
A avaliação do peso úmido e seco dos corações foi, também realizada com intuito de excluir a eventual ocorrência de edema intersticial do tecido miocárdico que pudesse ter ocorrido de modo diferenciado entre os grupos considerados, impondo interpretações distorcidas, particularmente nos animais que receberam decanoato de nandrolona. Não foi encontrada diferença estatística entre os grupos estudados, embora não seja possível através desta única mensuração excluir o aumento da massa ventricular, devido à sua composição de miócitos e de elementos intersticiais.

A decisão de realizar medidas semanais da pressão arterial dos animais foi baseada em dados de literatura que descrevem o aparecimento de hipertensão arterial em parte dos usuários de EAA (Llewellyn, 2000). Acredita-se que a hipertensão ocorra por causa da retenção hídrica e de sal por eles desencadeados. Tipicamente ela é descrita pelos usuários como transitória, resolvendo-se espontaneamente com a suspensão do uso do medicamento (Sullivan, 1998). Uma outra suposição é de que o aumento do volume sangüíneo total que ocorre em usuários de EAA pudesse também contribuir para esta elevação da pressão arterial, até que os mecanismos adaptativos da vasculatura pudessem normalizá-la. Estas alterações sangüíneas, em geral, demoram mais do que quatro semanas para aparecerem (Sullivan, 1989). Sabemos também que os andrógenos podem causar hipertensão de origem renal através da diminuição plasmática da vasopressina e pelo clareamento hepático de aldosterona (Sullivan, 1989). Wagner documentou que a expressão do RNA mensageiro da renina encontrados nas glândulas adrenais, rins e cérebro é tecido específico e andrógeno dependente, fato este que poderia perfeitamente explicar o aparecimento da hipertensão arterial (Wagner, 1990). 
No período do estudo não foi detectada qualquer elevação da pressão arterial em nenhum dos ratos estudados. Este achado é compatível com dados da literatura, que embora inconclusivos até este momento, acreditam que este indesejável efeito seja novamente dose, droga e tempo dependente (Kleiner, 1989; Thompson, 1992).

Os animais não foram treinados a realizar qualquer tipo de atividade física com objetivo de não se criar um viés no estudo da hipertrofia miocárdica, visto a prática esportiva levar ao aparecimento de alterações funcionais e anatômicas neste órgão, aumentando a sensibilidade dos receptores androgênicos. Lembramos que são muitos os mecanismos adaptativos do coração em resposta ao crescimento, ao exercício e outras mudanças fisiológicas que estão sob influência dos esteróides, sejam eles endógenos ou não (Kleiner, 1989; Hickson, 1984; Sullivan, 1998; Rockhold, 1993; Melchert, 1995).

O coração de atletas de resistência muscular de longa duração apresenta dimensão e volume diastólico maiores do que de indivíduos sedentários e atletas envolvidos em atividades de curta duração. O treinamento de resistência provoca aumento da massa ventricular e na função cardíaca como resposta adaptativa à atividade física (Robergs, 2002). Há igualmente aumento do septo interventricular, sendo todas estas alterações descritas independentes da utilização de EAA (Robergs, 2002). Esta resposta hipertrófica ao exercício restringe-se aos miócitos, não causando qualquer alteração na matriz extracelular ou fibrose intersticial; não são descritas igualmente alterações neurohumorais.

Baseados nos resultados da video-histomorfometria apresentados, podemos concluir que os EAA desempenham importante papel no processo de 
remodelamento ventricular, pois os animais estudados não ficaram hipertensos ao longo do estudo e não foram estimulados a realizar atividade física.

$\mathrm{Na}$ literatura, encontramos vários trabalhos ecocardiográficos realizados comparativamente entre fisiculturistas, que utilizam EAA e que não utilizam ou tinham suspendido meses antes, mostrando aumento significativo da massa ventricular esquerda e do septo interventricular. Este dado nos leva a entender que os EAA podem alterar patologicamente as adaptações fisiológicas que ocorrem com a realização de atividade física (Fleck, 1993; Sachtleben, 1993). Alguns acreditam que o uso simultâneo de um EAA junto a prática esportiva leve a um aumento da frequiência cardíaca e da pressão arterial que, por sua vez, resultará em hipertrofia ventricular esquerda compensatória e que esta combinação ocasione uma hipertrofia concêntrica na parede ventricular esquerda, além de disfunção diastólica (Urhausen, 1989; Trifunovic, 1995). Os EAA alterariam o remodelamento ventricular esquerdo induzido pelo exercício, reduzindo os benefícios fisiológicos secundários à prática esportiva, relacionado principalmente a alterações na microvasculatura (Tagarakis,2000; Woodiss, 2000). Dickerman e Luke relatam casos de cardiomegalia com hipertrofia concêntrica em usuários de altas doses de EAA (Dickerman, 1995; Luke, 1990).

O uso de esteróides, associados ou não à atividade física, resulta em várias alterações morfológicas e fisiológicas no coração similares às encontradas nos quadros iniciais de insuficiência cardíaca e cardiomiopatia (Sullivan, 1998; Kennedy, 1993; Luke, 1990; Ferenchick, 1998). No tecido cardíaco, sabemos que os EAA modulam a transcrição, a translação e exercem várias outras funções enzimáticas que poderiam estar relacionados a remodelação ventricular, baseando-se no controle androgênico 
exercido sobre estas funções, particularmente a regulação do crescimento celular (Gallant, 1991; Melchert, 1992; Sullivan, 1998; Koenig, 1982; Ferrer, 1994). Modelos realizados em várias espécies de animais mostram claramente o aparecimento de cardiomegalia após algumas semanas de uso destes fármacos (Pesola, 1988; De Picolli, 199). Um estudo necroscópico cardíaco realizado em jogadores de futebol americano, esporte este onde o emprego destes EAA é legal, mostrou grande desorganização miofibrilar, fibrose miocítica focal e espessamento da parede intramural das artérias (Kennedy, 1993). O ventrículo esquerdo, em suas regiões subepicárdicas, é o principal local de ocorrência de fibrose. Nos animais que utilizaram decanoato de nandrolona (ANA E ANA-ENA), durante três semanas, foi possível visualizar estas mesmas alterações descritas na literatura.

Koenig sugere que a testosterona poderia induzir, in vitro, os miócitos ventriculares de ratos a induzir as poliaminas a funcionarem como mensageiros intracelulares; estas por sua vez, ativariam a ornitina descaboxilase, estimulando a fluxo de cálcio e provocando alterações no transporte das membranas (Koenig, 1989). A lisil oxidase também está relacionada à redução da complacência ventricular esquerda secundária a administração de EAA (Legros, 2000). Assim uma alteração neste controle, propiciado pelo excesso de andrógenos circulantes, levaria a uma desorganização dos miócitos, que por sua vez alterariam a rede de matriz celular. A matriz tem como papel a manutenção da estrutura, de forma que a contração muscular seja efetiva. Estas alterações, finalmente, levariam a uma deposição excessiva de colágeno e a uma displasia intrafibrilar deste, que seria responsável em última instância pela progressão da disfunção no músculo cardíaco. 
Os EAA também seriam responsáveis pela redistribuição da síntese de colágeno que ocorreria transmuralmente.

Outra forma de atuação descrita dos EAA indica que eles causam alterações degenerativas nos neurônios simpáticos intracardíacos. A descrição deste fenômeno é acompanhada de processo regenerativo em aproximadamente seis semanas (Hartmann, 1986). Assim concluímos que, a toxicidade dos EAA causa perda da viabilidade celular, com subseqüentes alterações nas concentrações intracelulares de íons e conseqüentemente necrose e áreas fibróticas.

Em trabalho recém publicado demonstrou-se, in vitro, o aparecimento de apoptose em miócitos de ventrículo esquerdo de ratos expostos a EAA. Este achado, pode ter importantes implicações no entendimento da patogênese do remodelamento ventricular, na cardiomiopatia e na morte súbita associada ao abuso de EAA. É interessante ressaltar que a indução da morte celular por apoptose foi dose dependente (Zaugg, 2002).

Até este momento, não existe consenso na literatura sobre a persistência destas alterações descritas após a descontinuidade da droga e de seus efeitos tardios. São poucos os estudos de acompanhamento de uso prolongado dos EAA.

Quanto a hipertrofia miocárdica sabemos que ela é descrita como uma tentativa de adaptação do coração à sobrecarga de trabalho, evoluindo para falência cardíaca quando o processo de adaptação é esgotado (Leonetti, 1995). Alterações vasculares, aumento da espessura da parede dos vasos da microcirculação coronária, aumento da biossíntese de colágeno na parede vascular e mudanças na estrutura do miocárdio, como o remodelamento intersticial, com acúmulo de colágeno fibrilar 
fazem parte deste processo hipertrófico (Mandarim, 1995). Assim, concluímos assim que o remodelamento estrutural da matriz colágena faz progredir a disfunção ventricular até a falência cardíaca congestiva (Weber, 1990).

Sabendo que as alterações cardíacas secundárias ao uso de EAA são semelhantes as da insuficiência cardíaca em suas fases iniciais, surgiu-se a idéia de utilizar um IECA, sabidamente uma droga que atua sob a remodelação ventricular, com o objetivo de estudar seu eventual papel protetor. Junto a este dado, relacionamos o fato de que a expressão do RNA mensageiro da renina encontrados nas glândulas adrenais, rins e cérebro é específico e andrógeno dependente; eles seriam participantes da modulação dos receptores da angiotensina (Wagner, 1990). Assim poderíamos imaginar que o excesso de andrógeno circulante pudesse estimular esta via, desencadeando o aparecimento da fibrose, pois sabemos que a liberação da renina, responsável pela conversão do angiotensinogênio em angiotensina causa em última análise vasoconstricção, que por sua vez, estimula a secreção adrenal de Aldo. São inúmeros os trabalhos que relacionam o aumento de Ang II ou Aldo à fibrose dos ventrículos.

Os hormônios do SRRA também estimulam a secreção de endotelinas que, por sua vez, estimulam a produção de Ang II ou Aldo. In vitro, sabemos que, Ang II, Aldo e ET elevam os níveis de cálcio intracelular e este estaria, por sua vez, envolvido no aumento da produção de colágeno. A ação do SRAA também promove acúmulo de colágeno tipos I e III, aumentando a disfunção ventricular, tanto sistólica como diastólica. Esta teoria de desordem neurohumoral vem sendo, nos últimos anos, avaliada juntamente com as alterações mecânicas e hemodinâmicas na 
progressão da disfunção ventricular e poderia servir para explicar a fibrose induzida pelo uso de EAA.

Os IECA são drogas de fundamental papel na regressão, prevenção e aceleração da regressão da HVE (Dzau, 1988). O enalaprilato foi então utilizado neste trabalho com objetivo de prevenir o desenvolvimento do remodelamento ventricular desencadeado pelo uso do EAA. Esta droga já foi inúmeras vezes utilizada com sucesso na prevenção da hipertrofia ventricular induzida pela hipertensão arterial, no remodelamento ventricular da insuficiência cardíaca, entre outros. Seu principal mecanismo está baseado na inibição da enzima conversora da angiotensina. Esta inibição resulta no bloqueio da formação de Ang II, redução da resistência vascular periférica e conseqüentemente da pressão arterial. À medida que os níveis de Ang II caem, a atividade de renina plasmática aumenta e os níveis de Aldo caem. Trabalhos sugerem que a fibrose intersticial e perivascular depende primordialmente da Ang II circulante e tecidual e dos níveis de testosterona.

Sabemos também que os IECA previnem ou revertem o remodelamento miocárdico adverso, reduzindo a hipertrofia miocítica, bem como a densidade de colágeno. São efeitos que resultam tanto na redução da sobrecarga ventricular esquerda, como na inibição dos fatores estimulantes de crescimento da Ang II, nos cardiomiócitos e nos fibroblastos. Existem, igualmente, evidências experimentais de que mesmo doses não terapêuticas de IECA, insuficientes para tratar a hipertrofia cardíaca, podem prevenir a necrose dos miócitos e a fibrose miocárdica.

Como os grupos ANA e ANA-ENA tiveram comportamento igual frente ao remodelamento ventricular esquerdo induzida pelos EAA, podemos 
concluir que o IECA utilizado não exerceu efeito cardioprotetor e reparador, como esperado. Uma eventual explicação pela não resposta ao enalaprilato utilizado de forma concomitante ao decanoato de nandrolona, está no fato dos ratos não terem ficado hipertensos; sabemos que em indivíduos normotensos e com dieta de sódio normal, a administração de inibidores da ECA agudamente não exerce qualquer efeito. A renina destes animais também poderia estar normal, o que poderia er contribuído para uma menor atuação do enalaprilato sobre o SRAA. Outra hipótese aventada seria de dose e tempo utilizados terem sido insuficientes para a prevenção do quadro instalado. Ou de que esta droga é insuficiente para prevenir o aparecimento das alterações induzidas pelos EAA no colágeno cardíaco.

$\mathrm{Na}$ musculatura esquelética vários trabalhos sugerem que os EAA causariam destruição dos sarcolemas com grande desorganização das fibras citoesqueléticas. Eles deslocariam o cálcio para dentro das células causando um mau funcionamento das respectivas bombas e conseqüente ativação das proteases lipossomais. A desorganização mitocondrial que se sucede ativaria as proteases intracelulares tendo-se início o quadro de degradação protéica e uma intensa atividade inflamatória com destruição de parte dos miofilamentos. O estímulo dos monócitos e macrófagos, decorrentes do processo inflamatório, ativaria por sua vez as células satélites. Estas desempenham papel primordial na regeneração e reparação celular da musculatura esquelética, manifestada através da esperada hipertrofia muscular. Fazendo uma analogia entre a musculatura esquelética e a cardíaca, vemos que parte das alterações cardíacas encontradas após o uso de EAA assemelha-se muito àquelas encontradas na musculatura esquelética destes usuários, onde o desbalanço do cálcio muito contribui para o aparecimento da hipertrofia muscular. 
Talvez a utilização de antagonistas dos canais de cálcio, sabidamente drogas que alteram o influxo de cálcio transmembrana, concomitante a utilização de EAA traga novas informações sobre a fisiopatologia destas importantes alterações cardíacas secundárias a sua administração. Os antagonistas dos canais de cálcio causando bloqueio seletivo dos canais encontrados na membrana e inibindo o influxo de cálcio do espaço extracelular para o interior da célula poderiam evitar a ativação das proteases, do processo inflamatório e conseqüentemente dos processos reparativos e regenerativos, que no coração parecem ocorrer de forma desordenada. O uso de IECA em maior dosagem igualmente poderia exercer este papel.

Embora a toxicidade cardíaca associada ao uso de EAA seja de reprodutibilidade relativamente fácil em animais de experimentação, o número de estudos na literatura médica é ainda pequeno, permanecendo seu exato mecanismo ainda não elucidado. Portanto outros estudos serão necessários, lembrando principalmente do impacto na morbidade e mortalidade que o uso indiscriminado e abusivo do s EAA causam (Fineschi, 2001) e que esta desinformação muito contribui para o seu emprego. 
7. Conclusão 
Após a administração do decanoato de nandrolona com e sem a concomitância do enalaprilato, concluiu-se que:

$>$ Os esteróides anabólico-androgênicos induzem o remodelamento ventricular esquerdo de forma significante, quando são empregadas doses elevadas.

$>\quad$ O aparecimento do remodelamento ventricular pode ser constatado após três semanas de utilização dos esteróides anabólico-androgênicos.

$>\quad \mathrm{O}$ enalaprilato, um inibidor da enzima conversora da angiotensina, na dosagem empregada e no tempo utilizado, não teve implicação no remodelamento ventricular esquerdo induzida pelo uso do esteróide anabólicoandrogênico. 
8. ANEXos 
FigURA 1. Artigos de revistas e jornais (Schwarzenegger, 2001; Guimarães Neto, 2000; Jornal da Musculação, 2002; Carneiro, 1999; Lemonick, 1999; Tonica, 2000; Dickensheets, 2002).

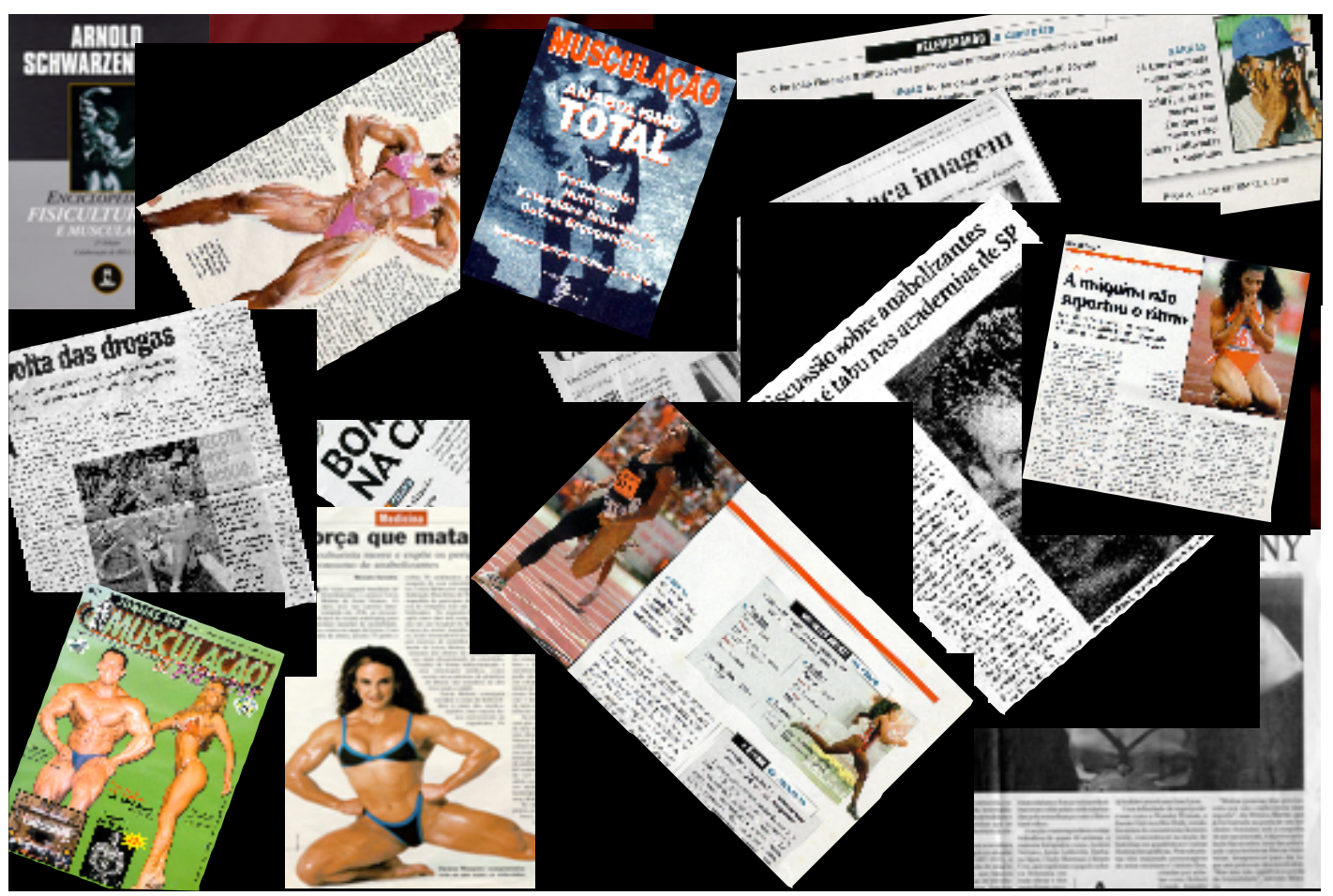

FIGURA 2. Olimpo, local onde foram primeiramente realizados os jogos olímpicos na Grécia (Mavromataki, 1997).

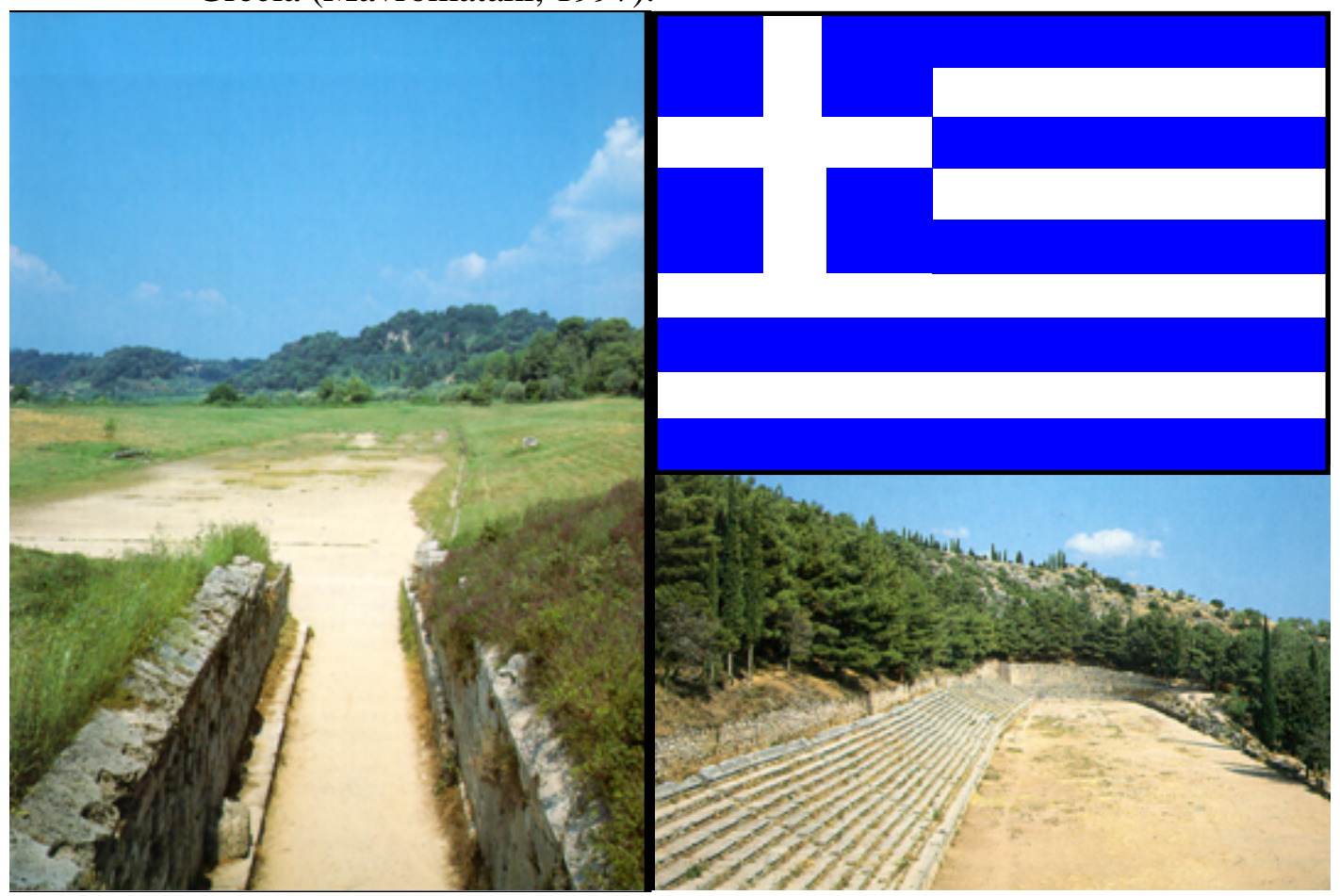


FigURA 3. Moeda da antiga Grécia com detalhe de um esportista, onde podemos ver a perfeição das formas físicas (Mavromataki, 1997).

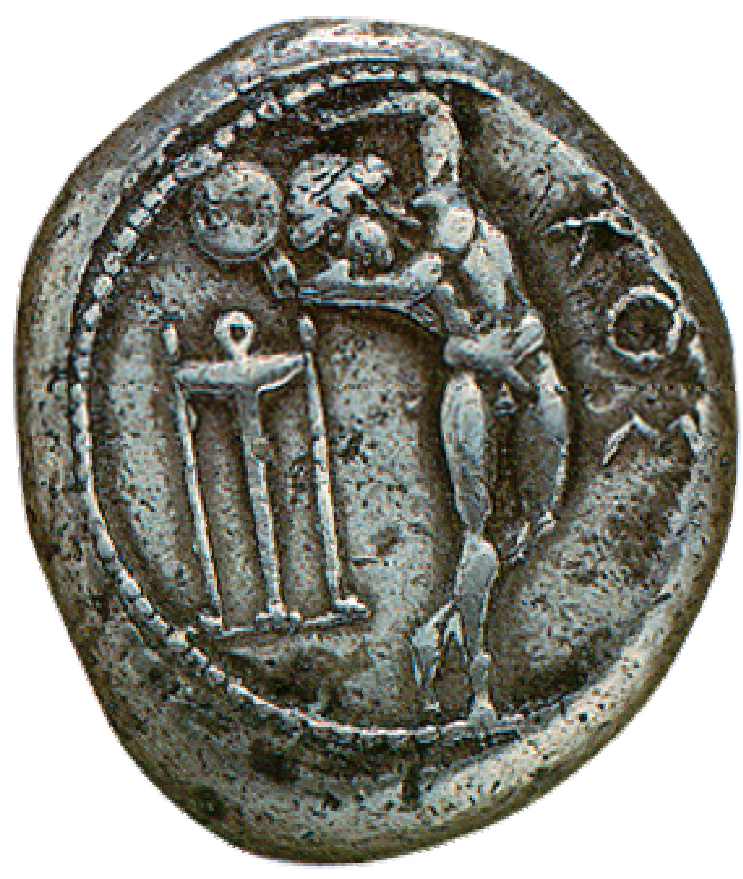

Figura 4. Caricatura da velocista Florence Joyner, publicada na revista Época, na semana de seu falecimento (Revista Época,1998).

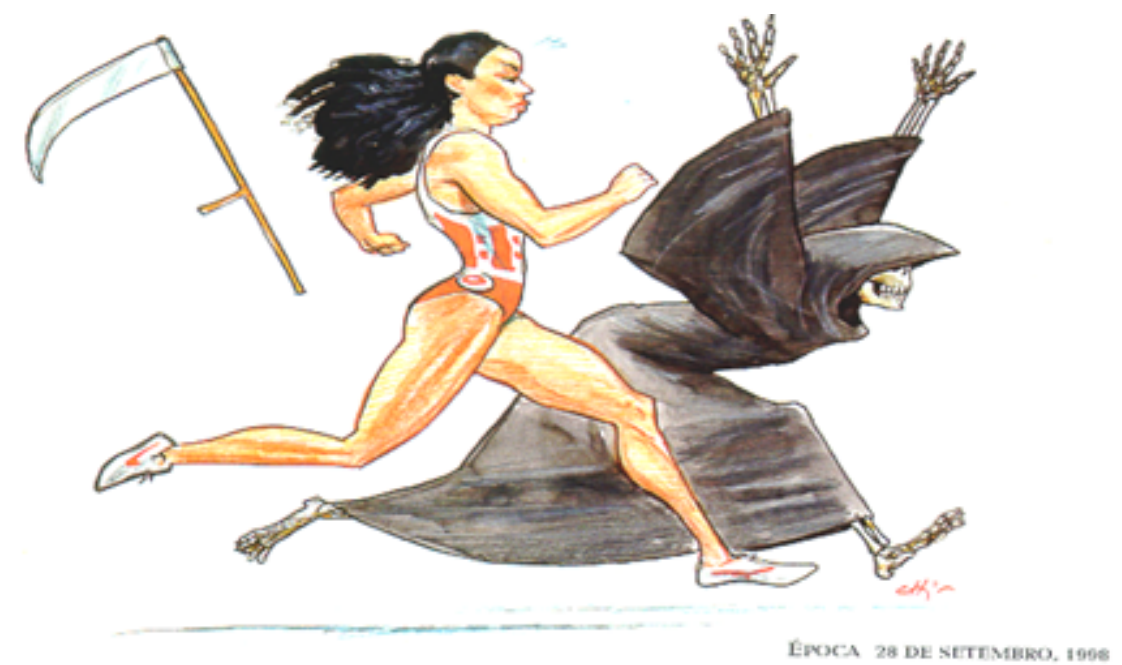


FigurA 5. Esquema de séries de utilização de anabolizantes, onde as doses empregadas são inúmeras vezes maiores que as recomendadas em bula dos produtos (Guimarães Neto, 2000).
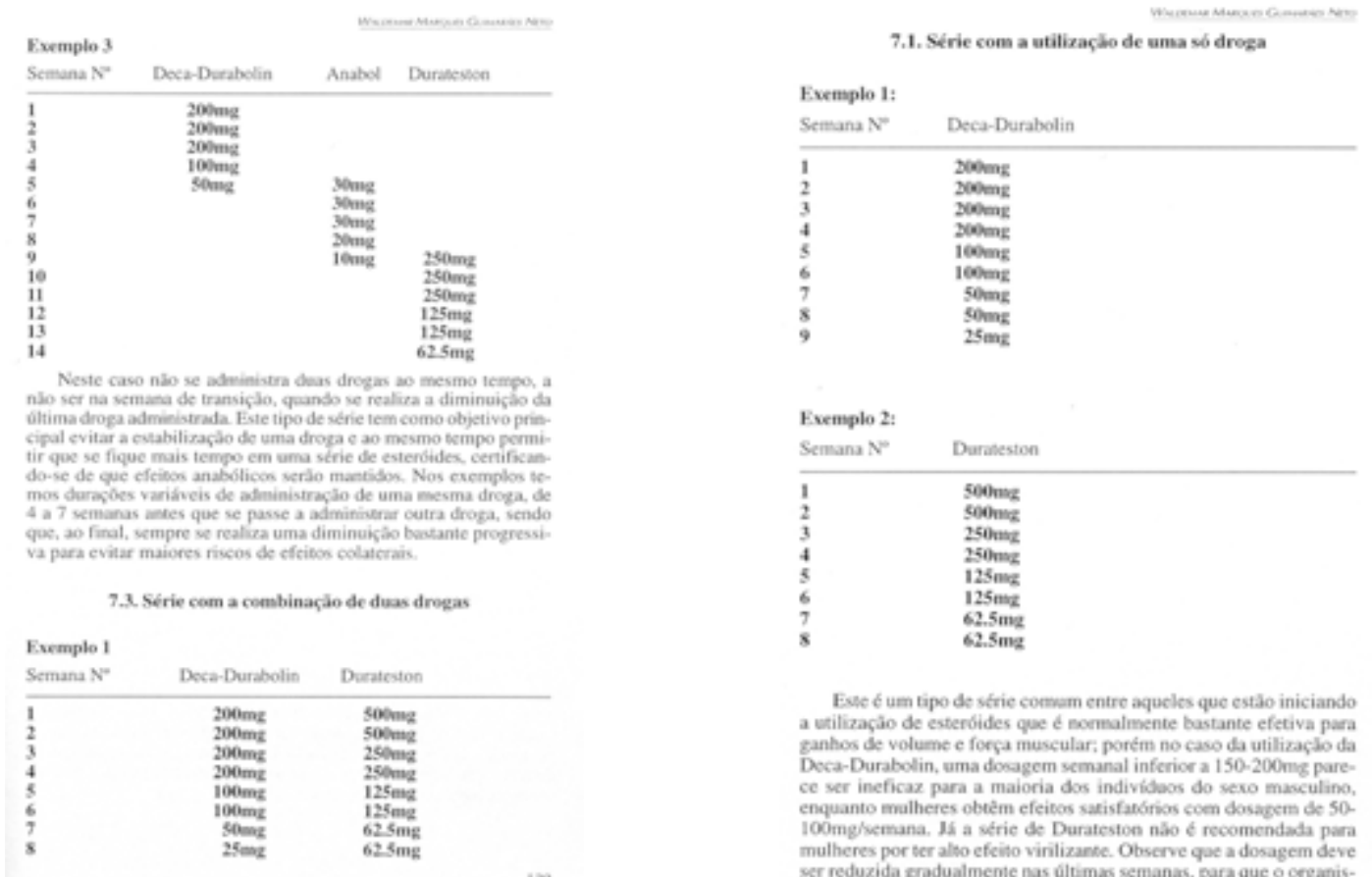

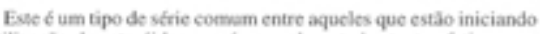
a vtilizaçâo de esteróides que é Boemalmente bastante efetiva para ginturs de volume e forya muscular; porém no caso da uthizac do da

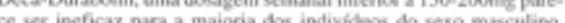

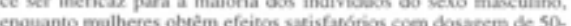

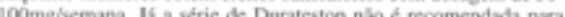

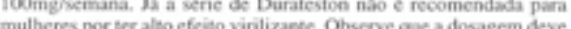
ser reduzida gradualmemie nas últimas semanas, para que o cog dentis-

Figura 6. Mecanismo de ação do decanoato de nandrolona.

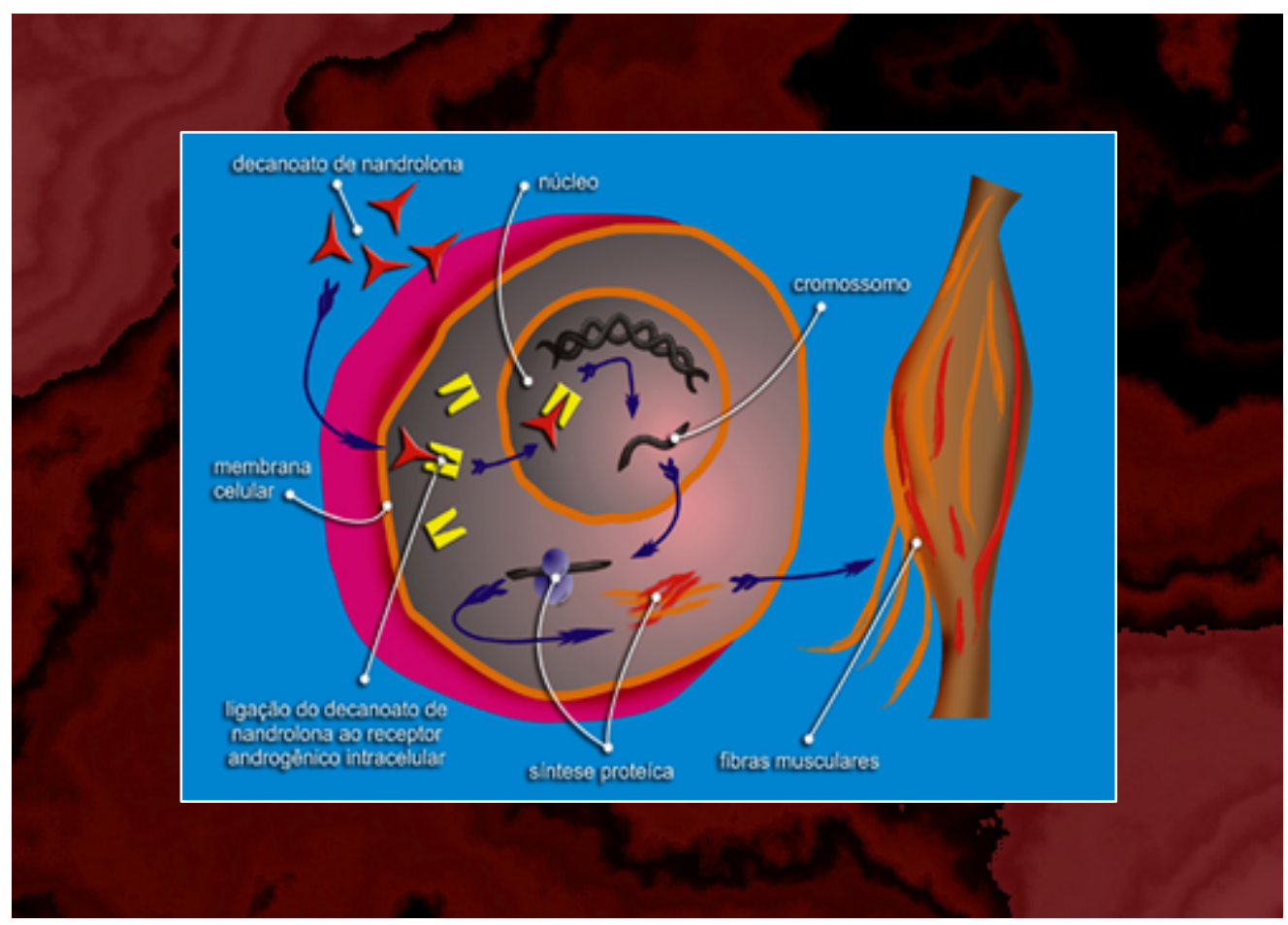


FIGURA 7. Esquema da realização dos procedimentos nos grupos ANA e CON.

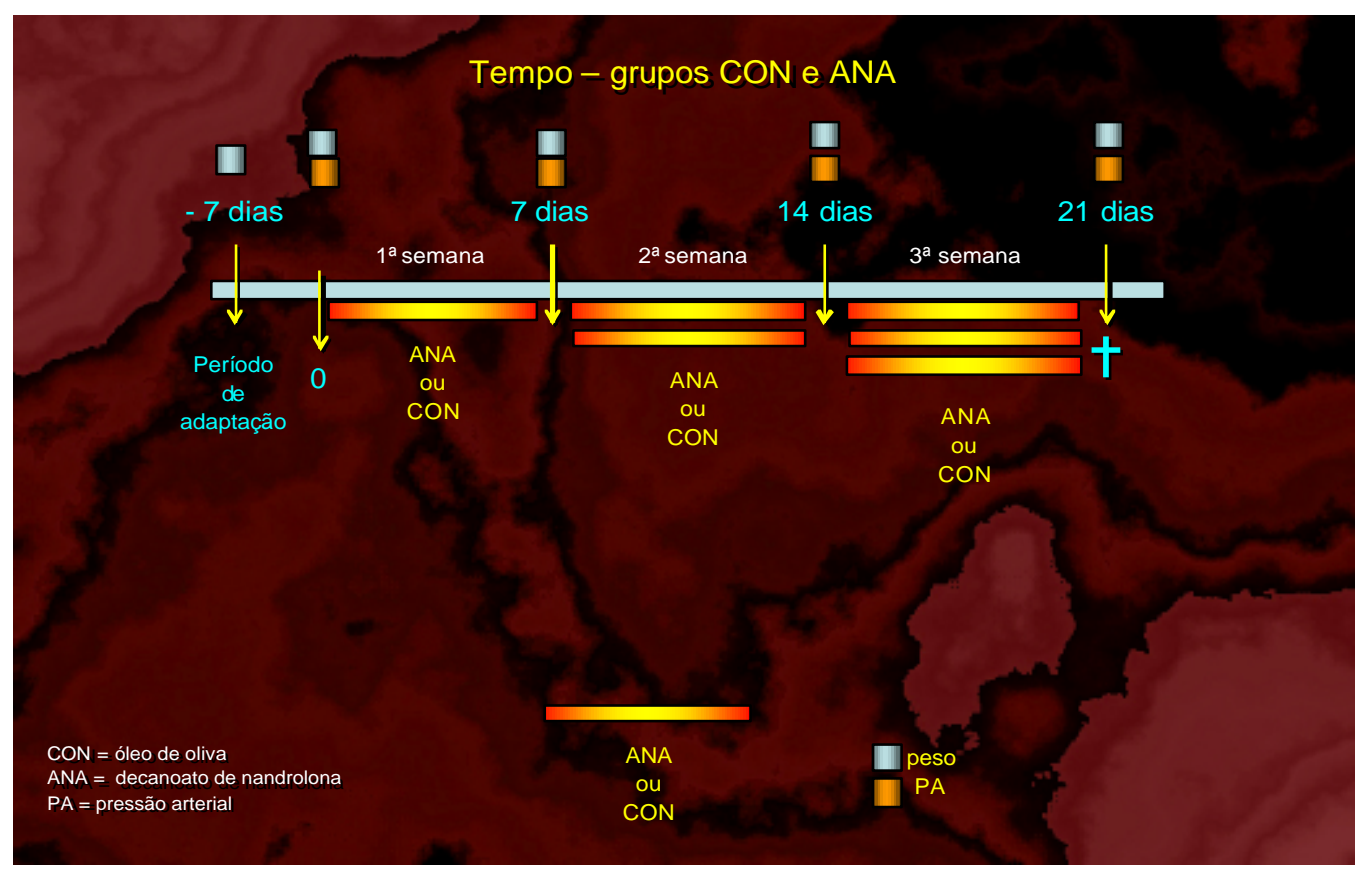

FIGURA 8. Esquema da realização dos procedimentos nos grupos ENA e ANA-ENA

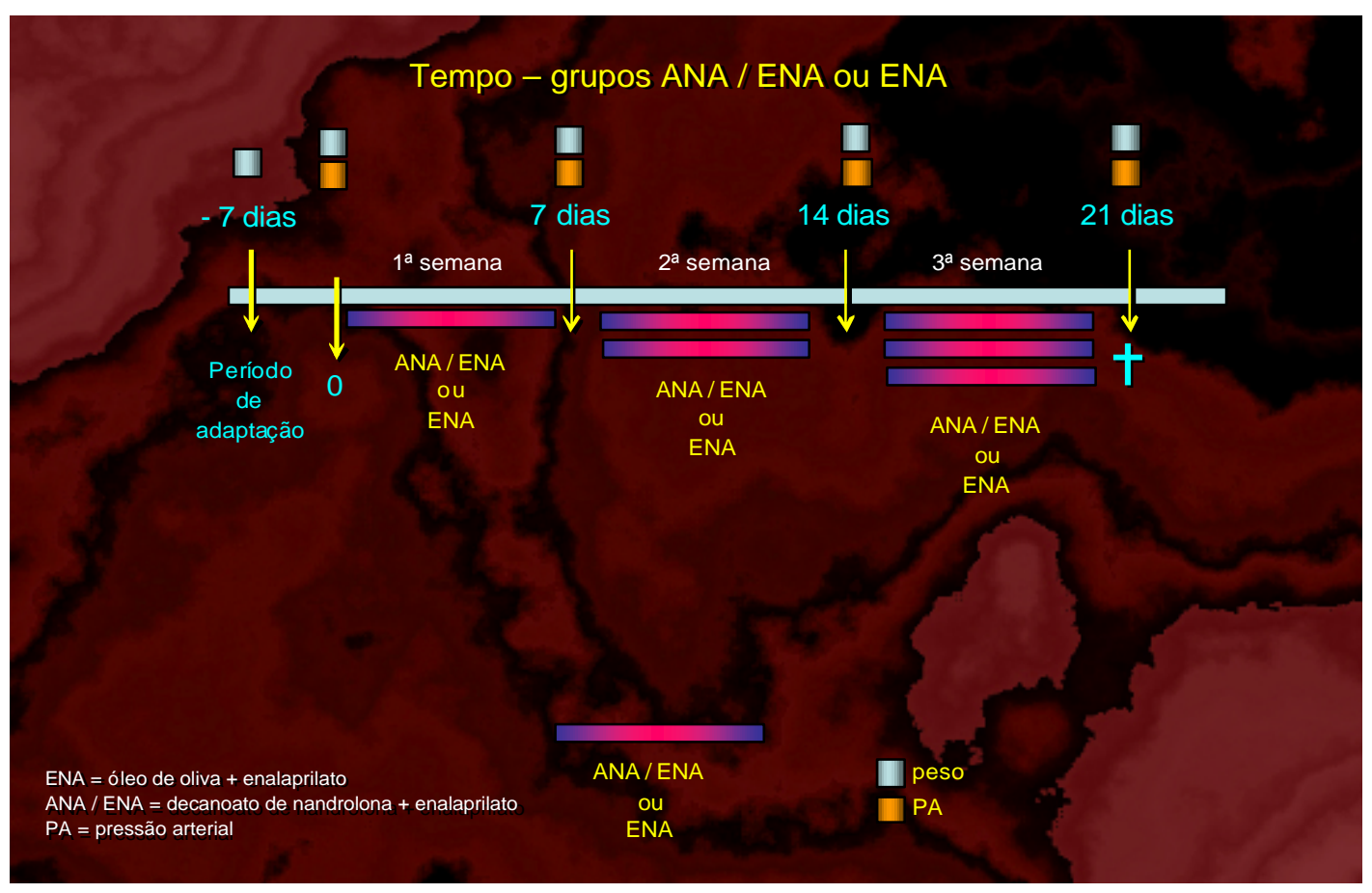


FIGURA 9. Lâmina de coração corado com picrosírius red dos grupos CON. (Magnificação de 20x)

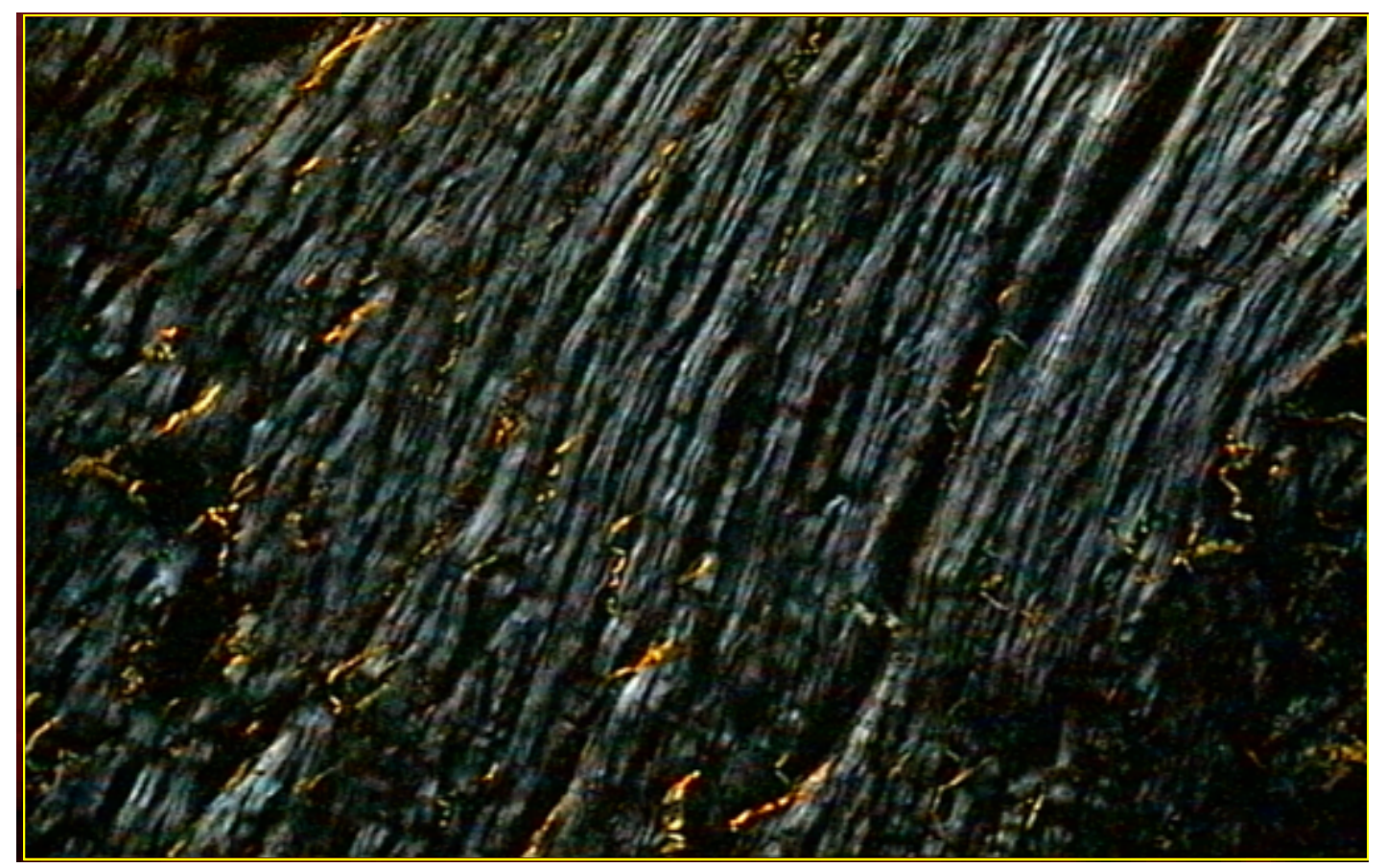

FIGURA 10. Lâmina de coração corado com picrosírius red dos grupos ANA. (Magnificação de 20x)

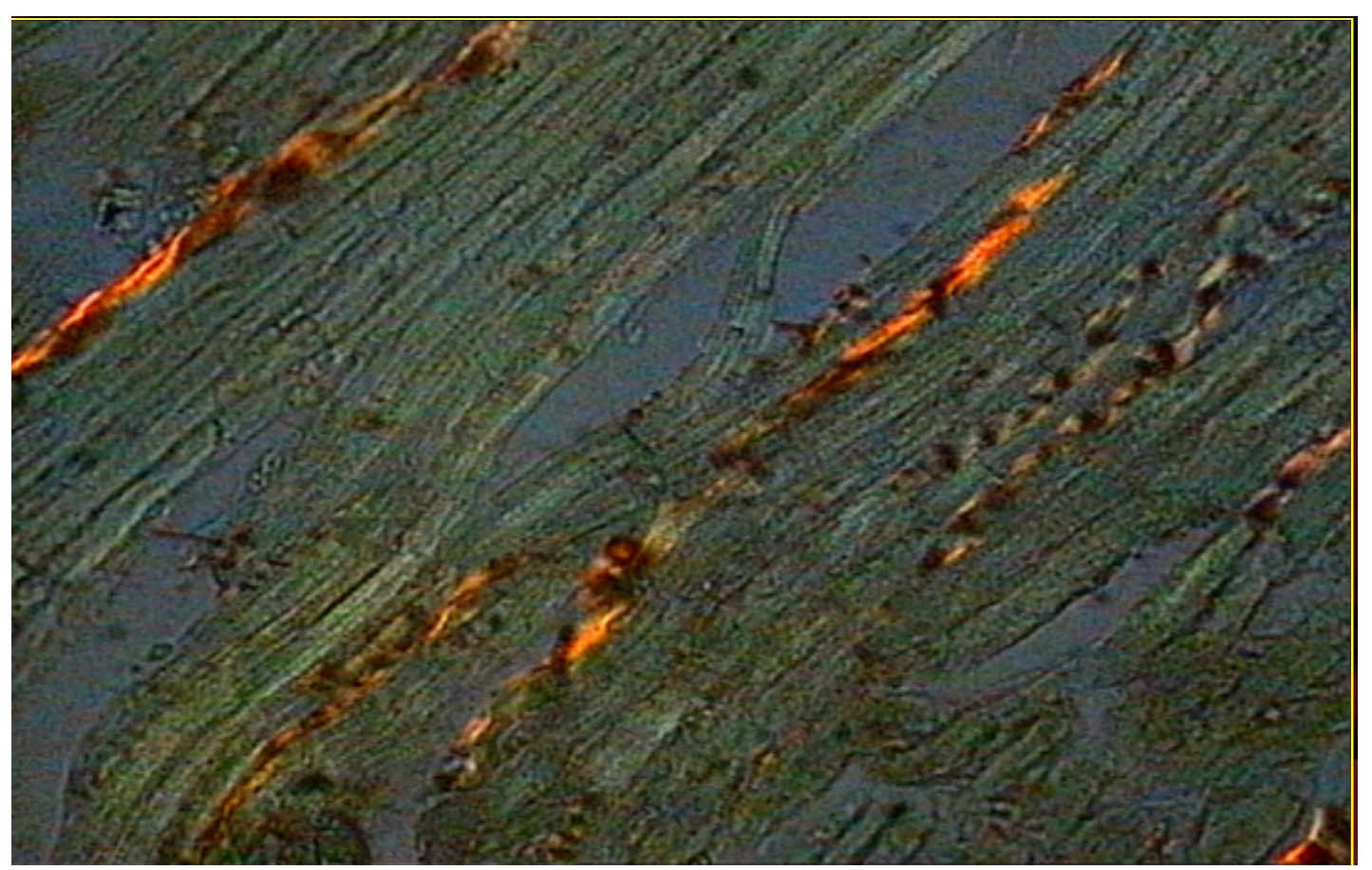


FIGURA 11. Lâmina de coração corado com picrosírius red dos grupos CON. (Magnificação de 20x)

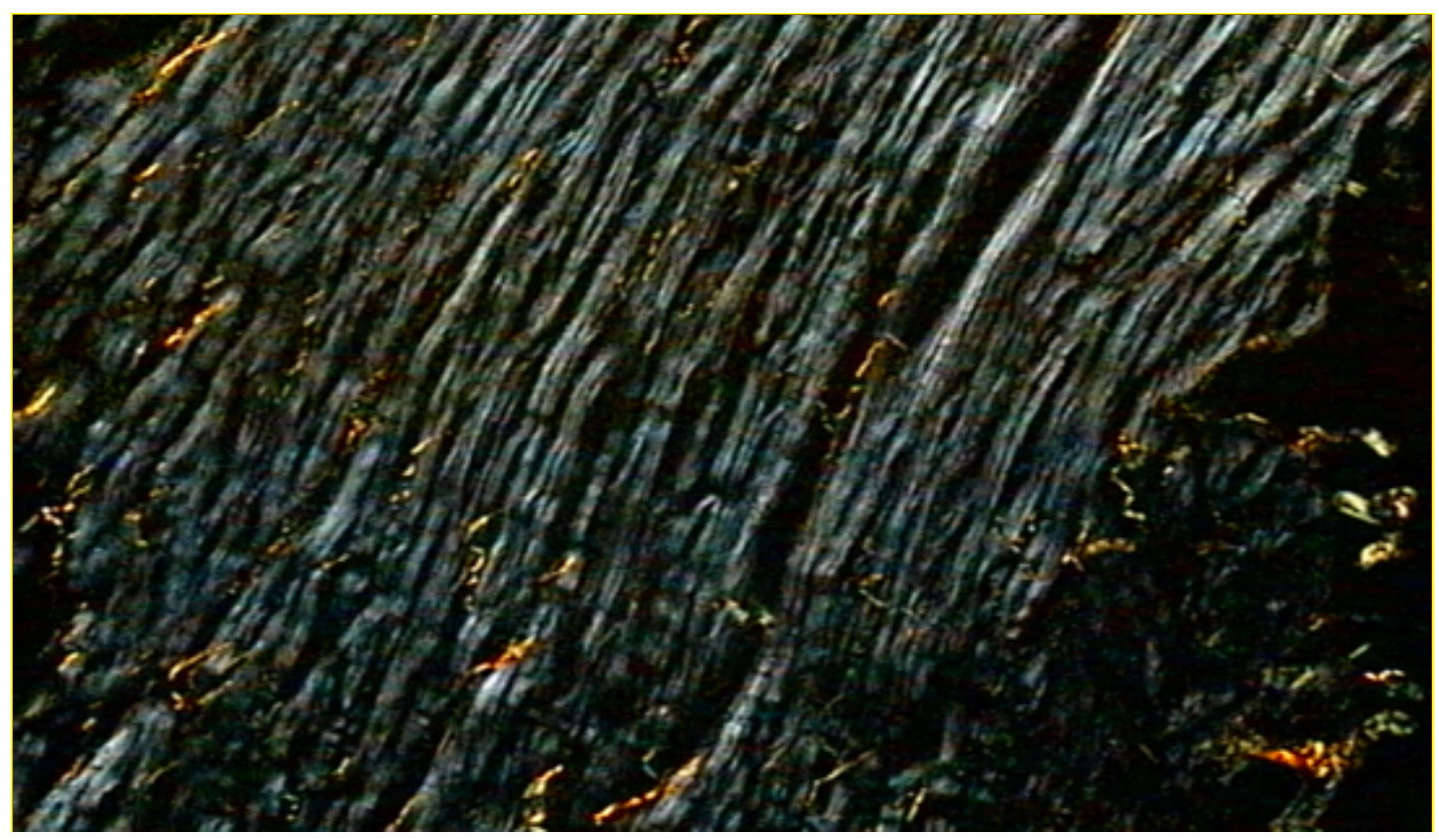

FIGURA 12. Lâmina de coração corado com picrosírius red dos grupos ANA-ENA. (Magnificação de 20x)

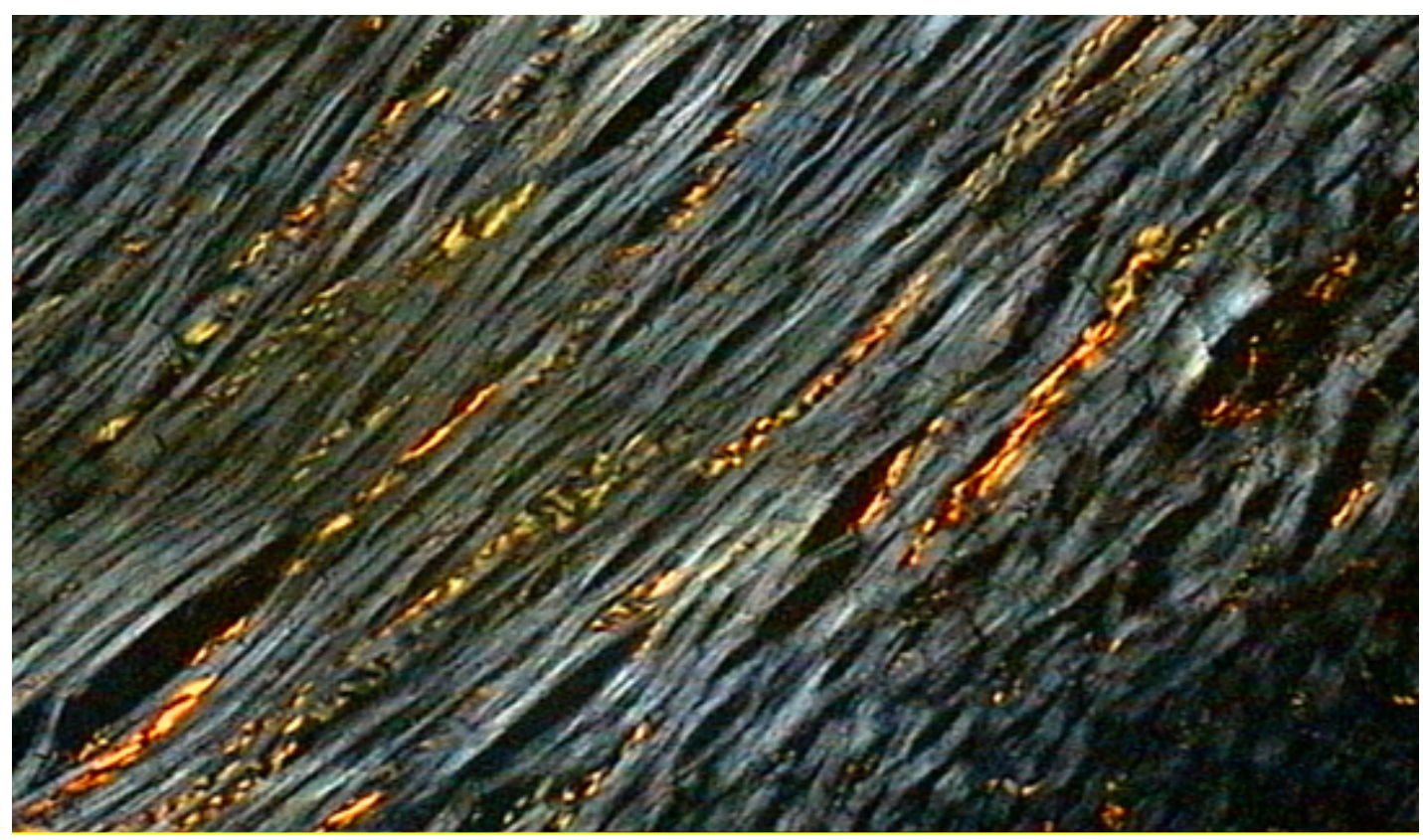


FIGURA 13. Lâmina de coração corado com picrosírius red dos grupos ANA.

(Magnificação de 20x)

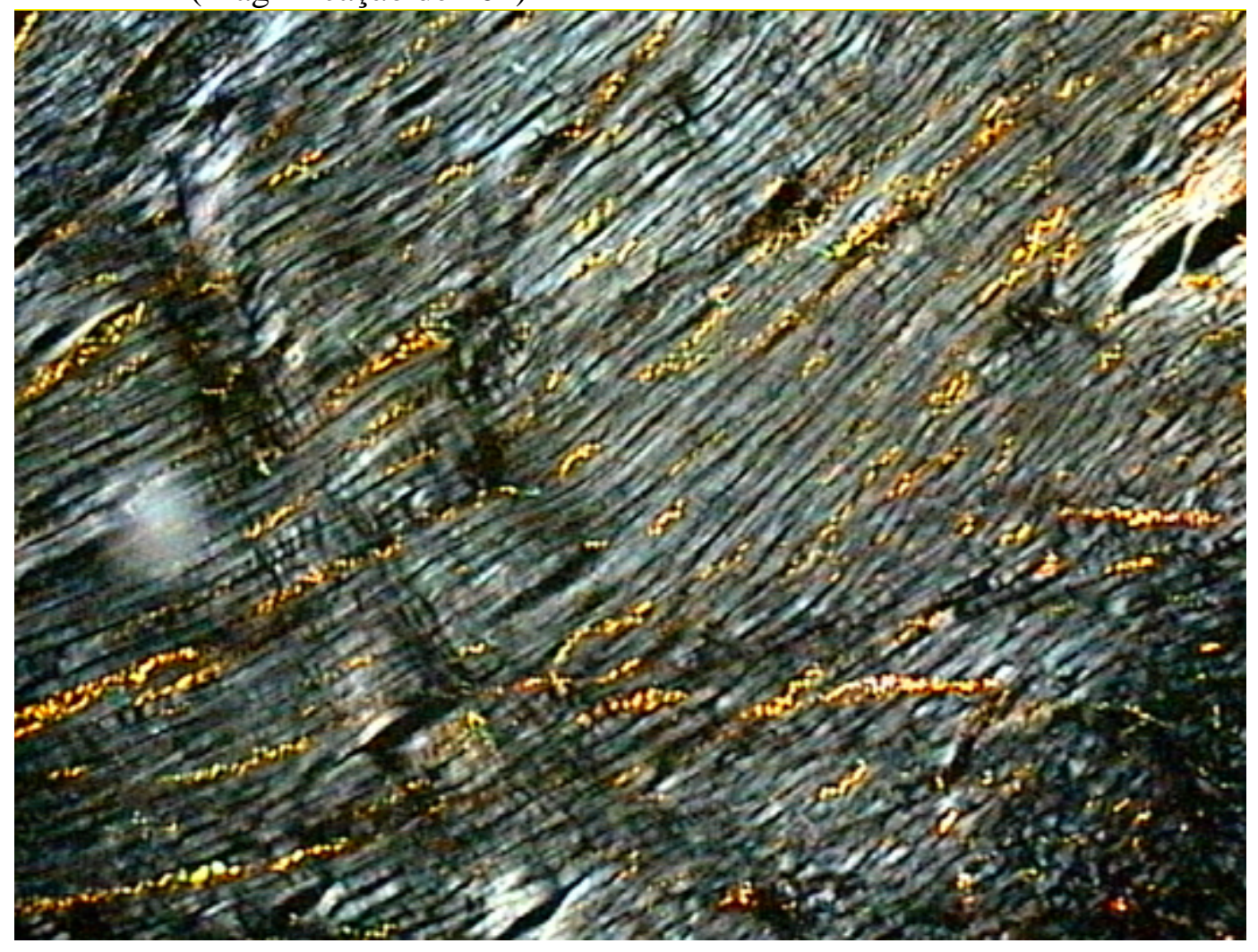

FIGURA 14. Lâmina de coração corado com picrosírius red dos grupos ANA-ENA. (Magnificação de 20x)

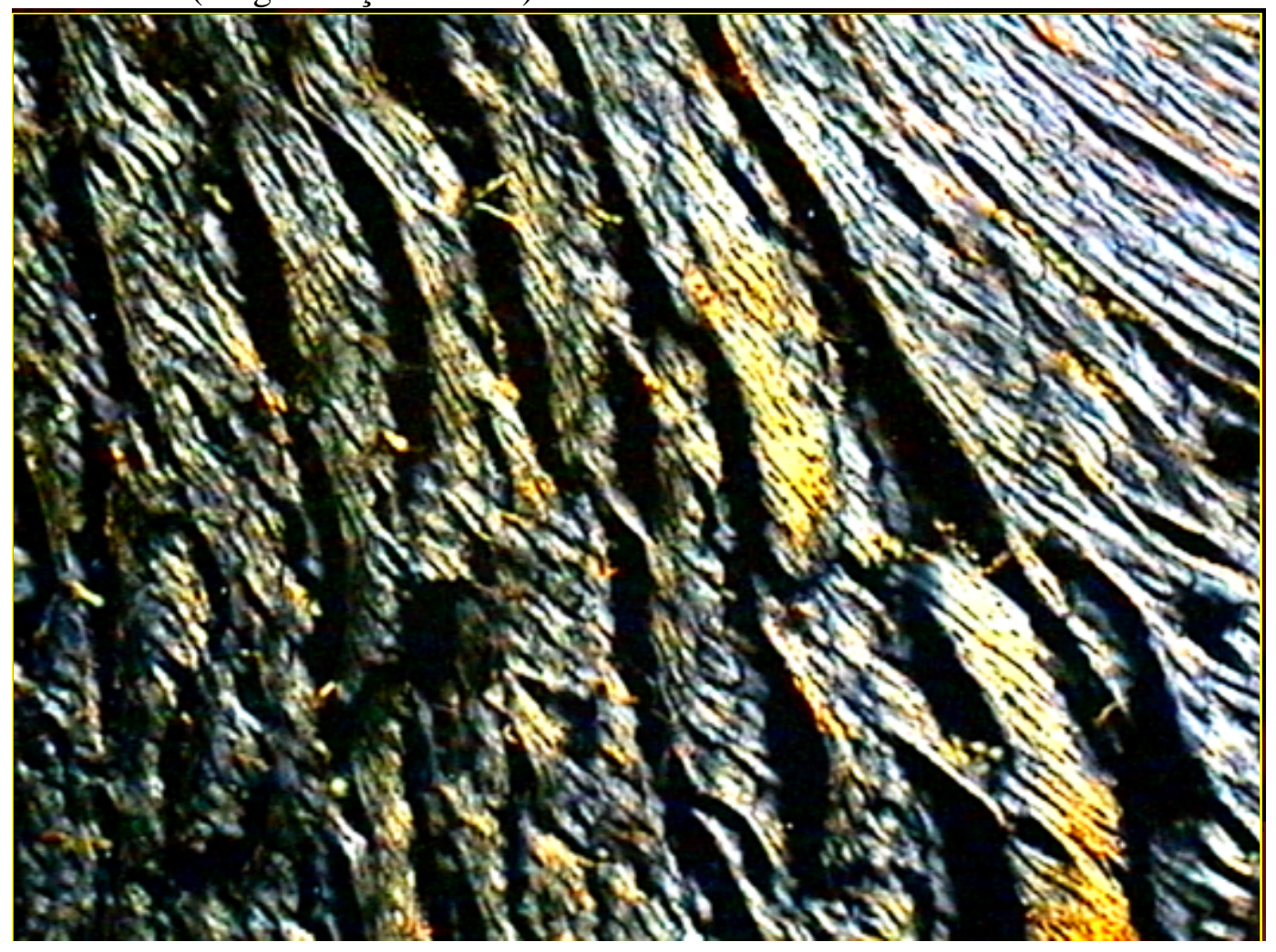


Quadro 1. Sinais comportamentais e corporais encontrados na quarta semana do experimento nos quatro grupos estudados.

\begin{tabular}{|c|c|c|c|c|c|c|c|c|c|c|c|c|c|c|}
\hline ANA & R01 & R02 & $\mathbf{R 0 3}$ & R04 & R05 & R06 & R07 & R08 & R09 & $\mathbf{R} 10$ & $\mathbf{R} 11$ & $\mathbf{R} 12$ & $\mathbf{R} 13$ & 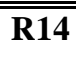 \\
\hline Agitação & $(+)$ & (+) & (+) & (+) & (-) & (+) & (-) & (+) & (+) & (+) & (-) & (+) & (-) & (+) \\
\hline Agressividade & $(-)$ & $(+)$ & $(+)$ & $(+)$ & $(-)$ & $(-)$ & $(+)$ & $(+)$ & $(+)$ & $(+)$ & $(-)$ & $(+)$ & $(-)$ & $(+)$ \\
\hline Pêlo eriçado & $(+)$ & $(+)$ & $(+)$ & $(+)$ & $(+)$ & $(+)$ & $(+)$ & $(+)$ & $(-)$ & $(+)$ & $(+)$ & $(+)$ & $(+)$ & $(+)$ \\
\hline Pêlo amarelado & $(+)$ & $(+)$ & $(+)$ & $(+)$ & $(+)$ & $(+)$ & $(+)$ & $(+)$ & $(+)$ & $(+)$ & $(+)$ & $(-)$ & $(+)$ & $(-)$ \\
\hline \multicolumn{15}{|l|}{ CON } \\
\hline Agitação & $(-)$ & $(-)$ & $(-)$ & $(-)$ & $(-)$ & $(-)$ & $(-)$ & $(-)$ & $(-)$ & $(-)$ & $(-)$ & $(-)$ & $(-)$ & $(-)$ \\
\hline Agressividade & $(-)$ & $(-)$ & $(-)$ & $(-)$ & $(-)$ & $(-)$ & $(-)$ & $(-)$ & $(-)$ & $(-)$ & $(-)$ & $(-)$ & $(-)$ & $(-)$ \\
\hline Pêlo eriçado & $(-)$ & $(-)$ & $(-)$ & $(-)$ & $(-)$ & $(-)$ & $(-)$ & $(-)$ & $(-)$ & $(-)$ & $(-)$ & $(-)$ & $(-)$ & $(-)$ \\
\hline Pêlo amarelado & $(-)$ & $(-)$ & $(-)$ & $(-)$ & $(-)$ & $(-)$ & $(-)$ & $(-)$ & $(-)$ & $(-)$ & $(-)$ & $(-)$ & $(-)$ & $(-)$ \\
\hline \multicolumn{15}{|l|}{ ENA } \\
\hline Agitação & $(-)$ & $(-)$ & $(-)$ & $(-)$ & $(-)$ & $(-)$ & $(-)$ & $(-)$ & $(-)$ & $(-)$ & $(-)$ & $(-)$ & $(-)$ & $(-)$ \\
\hline Agressividade & $(-)$ & $(-)$ & $(-)$ & $(-)$ & $(-)$ & $(-)$ & $(-)$ & $(-)$ & $(-)$ & $(-)$ & $(-)$ & $(-)$ & $(-)$ & $(-)$ \\
\hline Pêlo eriçado & $(-)$ & $(-)$ & $(-)$ & $(-)$ & $(-)$ & $(-)$ & $(-)$ & $(-)$ & $(-)$ & $(-)$ & $(-)$ & $(-)$ & $(-)$ & $(-)$ \\
\hline Pêlo amarelado & $(-)$ & $(-)$ & $(-)$ & $(-)$ & $(-)$ & $(-)$ & $(-)$ & $(-)$ & $(-)$ & $(-)$ & $(-)$ & $(-)$ & $(-)$ & $(-)$ \\
\hline \multicolumn{15}{|l|}{ ANA-ENA } \\
\hline Agitação & $(+)$ & $(+)$ & $(+)$ & $(+)$ & $(-)$ & $(+)$ & $(-)$ & $(+)$ & $(-)$ & $(+)$ & $(+)$ & $(+)$ & $(-)$ & $(+)$ \\
\hline Agressividade & $(+)$ & $(+)$ & $(+)$ & $(+)$ & $(-)$ & $(+)$ & $(+)$ & $(-)$ & $(+)$ & $(+)$ & $(+)$ & $(+)$ & $(-)$ & $(+)$ \\
\hline Pêlo eriçado & $(+)$ & $(-)$ & $(+)$ & $(+)$ & $(-)$ & $(+)$ & $(+)$ & $(+)$ & $(+)$ & $(+)$ & $(-)$ & $(+)$ & $(+)$ & $(+)$ \\
\hline Pêlo amarelado & $(+)$ & $(+)$ & $(+)$ & $(-)$ & $(+)$ & $(+)$ & $(-)$ & $(+)$ & $(+)$ & $(+)$ & $(+)$ & $(+)$ & $(+)$ & $(-)$ \\
\hline
\end{tabular}

ANA $=$ anabolizante CON $=$ controle ENA $=$ enalaprilato ANA-ENA $=$ anabolizante + enalaprilato $\mathbf{R}=$ rato $(-)=$ ausente $(+)=$ presente

$\mathrm{ANA} \approx \mathrm{ANA}-\mathrm{ENA} \neq \mathrm{CON}=\mathrm{ENA}$ 
TABela 1. Análise estatística do peso na quarta semana do experimento nos quatro grupos estudados.

\begin{tabular}{c|c|c|c|c}
\hline \hline Peso & ANA & CON & ENA & ANA-ENA \\
\hline \hline R01 & 354 & 286 & 312 & 366 \\
\hline R02 & 362 & 287 & 306 & 341 \\
\hline R03 & 309 & 249 & 291 & 276 \\
\hline R04 & 323 & 313 & 274 & 290 \\
\hline R05 & 318 & 280 & 306 & 331 \\
\hline R06 & 320 & 353 & 320 & 306 \\
\hline R07 & 320 & 323 & 253 & 272 \\
\hline R08 & 320 & 361 & 290 & 358 \\
\hline R09 & 306 & 280 & 290 & 284 \\
\hline R10 & 319 & 270 & 304 & 301 \\
\hline R11 & 348 & 275 & 292 & 264 \\
\hline R12 & 332 & 302 & 300 & 309 \\
\hline R13 & 388 & 254 & 294 & 286 \\
\hline R14 & 330 & 259 & 299 & 326 \\
\hline Média & 332,07 & 292,29 & 295,07 & 307,86 \\
\hline Mediana & 321,5 & 283 & 296,5 & 303,56 \\
\hline Desvio Padrão & 22,97 & 34,51 & 16,54 & 32,22 \\
\hline \hline
\end{tabular}

Análise de variância de Anova Kruskal Wallis e Teste de DUN Significante, $p<0.05$ e intervalo de confiança de $95 \%$

ANA = anabolizante CON = controle ENA = enalaprilato ANA-ENA = anabolizante + enalaprilato

$\mathbf{R}=$ rato Valores expressos em gramas

ANA $=$ ANA-ENA $>$ CON $=$ ENA 
TABELA 2. Análise estatística do comportamento do peso seco dos corações nos quatro grupos estudados.

\begin{tabular}{c|c|c|c|c}
\hline \hline Peso úmido & ANA & CON & ENA & ANA-ENA \\
\hline \hline R01 & 10.352 & 8.536 & 11.182 & 11.017 \\
\hline R02 & 9.154 & 8.967 & 10.729 & 11.392 \\
\hline R03 & 8.679 & 7.997 & 9.865 & 7.883 \\
\hline R04 & 9.117 & 9.102 & 9.007 & 8.276 \\
\hline R05 & 9.964 & 9.078 & 9.348 & 11.038 \\
\hline R06 & 10.022 & 9.943 & 9.735 & 9.781 \\
\hline Média & $\mathbf{8 . 0 6 0}$ & 8.834 & 9.964 & 9.819 \\
\hline \hline Mediana & 9.335 & 8.660 & 10.068 & 9.385 \\
\hline \hline
\end{tabular}

Análise de variância de Anova Kruskal Wallis

Não significante, $p<0.05$ e intervalo de confiança de $95 \%$

ANA = anabolizante CON = controle ENA = enalaprilato ANA-ENA = anabolizante + enalaprilato

$\mathbf{R}=$ rato $\quad$ Valores expressos em miligramas

ANA $=$ ANA-ENA $=$ CON $=$ ENA 
TABEla 3. Análise estatística do comportamento do peso úmido dos corações nos quatro grupos estudados.

\begin{tabular}{c|c|c|c|c}
\hline \hline Peso úmido & ANA & CON & ENA & ANA-ENA \\
\hline \hline R01 & 10.352 & 8.536 & 11.182 & 11.017 \\
\hline R02 & 9.154 & 8.967 & 10.729 & 11.392 \\
\hline R03 & 8.679 & 7.997 & 9.865 & 7.883 \\
\hline R04 & 9.117 & 9.102 & 9.007 & 8.276 \\
\hline R05 & 9.964 & 9.078 & 9.348 & 11.038 \\
\hline R07 & 10.022 & 9.943 & 9.735 & 9.781 \\
\hline Média & 8.060 & 8.834 & 9.964 & 9.819 \\
\hline \hline Desvio Padrão & 9.335 & 8.660 & 10.068 & 9.385 \\
\hline \hline
\end{tabular}

Análise de variância de Anova Kruskal Wallis Não significante, $p<0.05$ e intervalo de confiança de $95 \%$

ANA = anabolizante CON = controle ENA = enalaprilato ANA-ENA = anabolizante + enalaprilato

$\mathbf{R}=$ rato Valores expressos em miligramas

ANA $=$ ANA-ENA $=$ CON $=$ ENA 
TABELA 4. Análise estatística do comportamento da pressão arterial caudal nos quatro grupos estudados.

\begin{tabular}{c|c|c|c|c}
\hline \hline PAS $(\mathbf{m m} \mathbf{H g})$ & $\mathbf{1}^{\mathbf{0}}$ semana & $\mathbf{2}^{\mathbf{0}}$ semana & $\mathbf{3}^{\mathbf{0}}$ semana & $\mathbf{4}^{\mathbf{0}}$ semana \\
\hline \hline ANA & 136 & 124 & 124 & 123 \\
\hline CON & 126 & 123 & 121 & 123 \\
\hline ENA & 129 & 134 & 129 & 127 \\
\hline ANA-ENA & 126 & 126 & 126 & 134 \\
\hline Média & 130 & 123,25 & 129,75 & 128 \\
\hline Mediana & 130 & 123 & 129 & 126 \\
\hline Desvio Padrão & 6,9 & 2,1 & 2,9 & 4 \\
\hline \hline
\end{tabular}

\begin{tabular}{c|c|c|c|c}
\hline \hline PAD (mm Hg) & $\mathbf{1}^{\mathbf{0}}$ semana & $\mathbf{2}^{\mathbf{0}}$ semana & $\mathbf{3}^{\mathbf{0}}$ semana & $\mathbf{4}^{\mathbf{0}}$ semana \\
\hline \hline ANA & 86 & 88 & 88 & 79 \\
\hline CON & 81 & 84 & 83 & 84 \\
\hline ENA & 81 & 87 & 82 & 79 \\
\hline ANA-ENA & 80 & 82 & 80 & 88 \\
\hline Média & 85,25 & 83 & 82,25 & 82,55 \\
\hline Mediana & 87 & 83,5 & 81,5 & 81 \\
\hline Desvio Padrão & 4,3 & 1,4 & 3,4 & 3,8 \\
\hline \hline
\end{tabular}

Análise de variância de Anova Kruskal Wallis

Não significante, $p<0.05$ e intervalo de confiança de $95 \%$

ANA = anabolizante CON = controle ENA = enalaprilato ANA-ENA = anabolizante + enalaprilato

PAS = pressão arterial sistólica PAD = pressão arterial diastólica

ANA $=$ ANA-ENA $=$ CON $=$ ENA 
TABELA 5 Análise estatística da fração do volume de colágeno intersticial do ventrículo esquerdo nos quatro grupos estudados.

\begin{tabular}{cc|c|c|c}
\hline \hline VE & ANA & CON & ENA & ANA-ENA \\
\hline \hline FVCI (\%) & 1.314 & 1.085 & 1.085 & 2.300 \\
\hline Média & 1.147 & 1.040 & 1.043 & 1.561 \\
\hline Mediana & 1.146 & 1.071 & 0.997 & 1.508 \\
\hline Desvio Padrão & 1.126 & 2.548 & 2.263 & 3.443 \\
\hline \hline
\end{tabular}

Análise de variância de Anova Kruskal Wallis e Teste de DUN

Significante, $p<0.05$ e intervalo de confiança de $95 \%$

ANA $=$ anabolizante CON $=$ controle ENA $=$ enalaprilato ANA-ENA $=$ anabolizante + enalaprilato

VE = ventrículo esquerdo FCVI = fração do volume de colágeno intersticial

ANA $=$ ANA-ENA $>$ CON $=$ ENA 
TABELA 6. Análise estatística da quantificação miocítica nos quatro grupos estudados.

\begin{tabular}{c|c|c|c|c}
\hline \hline & ANA & CON & ENA & ANA-ENA \\
\hline \hline Média & 6.962 & 6.300 & 7.928 & 6.212 \\
\hline Mediana & 6.850 & 6.350 & 6.782 & 6.000 \\
\hline Desvio Padrão & 1.373 & 1.374 & 1.267 & 1.363 \\
\hline \hline
\end{tabular}

Análise de variância de Anova Kruskal Wallis

Não significante, $p<0.05$ e intervalo de confiança de $95 \%$

ANA = anabolizante CON $=$ controle ENA $=$ enalaprilato ANA-ENA $=$ anabolizante + enalaprilato

ANA $=$ ANA-ENA $=$ CON $=$ ENA 
9. REFERÊNCIAS BIBLIOGRÁFICAS

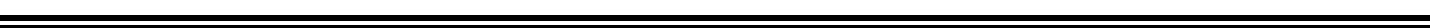


ALEXANDER, R.W.; EHSTEIN, L.S.; ATKINSON, R.W.; GIMBRAINE, M.A. Angiotensin increases cytosolic free calcium in cultured vascular smooth muscle cell. Hypertension, v. 07, p. 1105-1109, 1985.

ARANGO, H.G. Bioestatística: teórico e computacional. 1 ำ edição. Rio de Janeiro, Guanabara Koogan, 2001.

APPELL, H. J.; HELLER-UMPFENBACH, B.; FERAUDI, M.; WECKER, H. Ultra structural and morphological investigation on the effects of training and administration of anabolic steroids on the myocardium of guinea pigs. Int. J. Sports Med, v. 04, p. 268-274, 1983.

BACURAU, R. F. Nutrição e Suplementação Esportiva. $2^{\circ}$ edição. São Paulo, Phorte Editora, 2001.

BAKER, P.J.; RAMEY, E.R.; RAMWELL, P.W. Androgen-mediated sex differences of cardiovascular responses in rats. Am. J. Phisiol., v. 235, p. H242H246, 1978.

BEHRENDT, H.; BOFFIN, H. Myocardial Cell Lesions Caused by Anabolic Hormone. Cell Tiss. Res., v. 181, p. 423-426, 1977.

BOREK, M., CHRALAP, S., FRISMAN, W.H. Angiotensin-converting enzyme inhibitors in the heart failure. Med. Clin. N. Amer., v. 73, p. 315-338, 1989. 
BONÃG, R.D. Validation in awake rats of a tail-cuff method for measuring systolic pressure. Journal of Applied Physiology, v. 34, p. 279-282, 1973

BRILLA, C.G.; ZHOU, G.; MATSUBARA, L.; WEBER, K.T. Collagen metabolism in cultured adult rat cardiac fibroblast: response to angiotensin II and aldosterone. J. Mol. Cell Cardiol., v. 26, p. 809-820, 1994.

BRILLA,C.G.; SCHEER,C.; RUPP, H. Renin-angiotensin system and myocardial collagen matrix: modulation of cardiac fibroblast function by angiotensin II type 1 receptor antagonism. J. Hypert., v. 15, p. S13-S19, 1997.

BROCK, T.A.; ALEXANDER, R.W.; EKSTEIN, L.S.; et al. Angiotensin increases cytosolic free calcium in cultured vascular smoth muscle cells. Hypertension, v.7, p. 1105-1109, 1985.

BORG, T.K.; TERRACIO, L.; RUBIN, K.; SAMAREL, A. The cell biology of the cardiac interstitial. Trends Cardiovasc. Med., v. 06, p. 65-70, 1995.

CAMPBELL, S.E.; FARB, A.; WEBER, K.T. Pathologic remodeling of the myocardium in a weightlifters taking anabolic steroids. Blood Press, v. 02, p. 213216, 1993.

CARNEIRO, M. Força que mata. Revista Veja, São Paulo, Editora Abril, 1999. 
CHINERY, S. In Quest of Size - Anabolics and other Ergogenic Aids. $1^{\circ}$ edição. Estados Unidos, L \& S Publishing, 1984.

CLEUTJENS, J.P.M.; VERLUYTEN, M.J.A.; SMITS, J.F.M.; DAEMEN, M.J.A.P. Collagen remodeling after myocardial infarction in rat heart. Am. J. Pathol., v. 147, p. 325-338, 1995.

COKER, M.L.; SPINALE, F.G. Myocardial extra cellular matrix remodeling with the development of pacing induced congestive heart failure: contributory mechanisms. Cardiovasc. Pathol., v. 07, p. 161-168, 1998.

CONACHER, G.N.; WORKMAN, D.G. Violent crime possibly associated with anabolic steroid use. Am. J. Psychiatry, v. 146, p. 679, 1989.

COOPER, G. Cardiocyte adaptation to chronically altered load. Ann. Rev. Physiol., v. 49 , p. 501-518, 1987.

COUNCIL on SCIENTIFIC AFFAIRS. Medical and nonmedical uses of anabolicandrogenic steroids. JAMA, v. 264, p. 22, 1990.

CRAWFORD, D.C.; CHOBANIAN, A.V.; BRECHER, P. Angiotensin II induces fibronectin expression associated with cardiac fibrosis in the rat. Circ. Res., v. 74, p. 727-739, 1994. 
CRUICKSHANK, J.M.; LEWIS, J., MOORE, V.; et al. Reversibility of left ventricular hypertrophy by differing types of antihypertensive therapy. J. Hum. Hypertens., v. 06, p. 85-90, 1992.

DALBY, J.T. Brief anabolic steroid use and sustained behavioral reaction. Am. J. Psychiatry, v. 149, p. 271-272, 1992.

DAHLOF, P.; PENNERT, K., HANSSON, L. Reversal of left ventricular hypertrophy in hypertensive patients: a meta-analysis of 109 patients' treatment study. Am. J. Hypertens., v. 05, p. 95-110, 1992.

DE PICOLI, B.F.; GIADA, F.; BENETETTIN, A.; et Al. Anabolic steroid use in body builders: An echocardiograph study of left ventricular morphology and function. Int. J. Sports Med., v. 12, p. 408-412, 1991.

DICKERMAN, R.D.; SCHALLER, F.; PRATHER, I.; MCCONATHY, W.J. Sudden cardiac death in a 20 year old bodybuilder using anabolic steroids. Cardiology, v. 86, p. 172-173, 1995.

DICKENSHEETS, S. Bomba na cabeça. Revista Playboy, São Paulo, Editora Abril, 2002.

DIEZ, J.; LAVIADES, C. Monitoring fibrilar collagen turnover in the hypertensive heart disease. Cardiovasc. Res., v. 35, p. 20-205, 1997. 
DZAU, V.J. Molecular and physiological aspects of tissue renin-angiotensin system: Emphasis on cardiovascular control. J. Hypertension, v. 06, p. S7-S12, 1988.

FERENDICK, G.S. Association of steroid abuse with cardiomiopathy in athletes. Am. J Cardiol., v. 91, p. 562, 1991.

FERREIRA, S. A. Bradykinin - Potentiating Factor (BPF) present in the venom of Bothrops jararaca. Br. J. Pharmacol., v. 24, p. 163-169, 1965.

FERRER, M.; ENCABO, A.; MARIN, J; BALFAGON, G. Chronic treatment with anabolic steroid nandrolone, inhibits vasodilatary responses in rabbit aorta. Eur. J. Pharmacol., v. 252, p. 233- 241, 1994.

FINESCHI, V.; BAROLDI, G.; MANCIOTTI, F.; et al. Anabolic steroid abuse and cardiac sudden death: a pathologic study. Arch. Pathol. Lab. Med., v. 125, p. 253$255,2001$.

FLECK S.J.; PATTANY, P.M.; STONE, M.H., et al. Magnetic resonance imaging determination of left ventricular mass: junior Olympic weightlifters. Med. Sci. Sports Exer., v. 25, p. 522-527, 1993.

GALlANT, S.; ALFANO, J.; CHARPIM, M.; BROWINIE, A.C. Expression of adrenal cytochromes P450 in testosterone induced hypertension. Hypertension, $v$. 18, p. 523-528, 1991. 
GREEN, D.J.; CABLE, N.T; RANKIN, J.M; et al. Anabolic steroids and vascular responses. Lancet, v. 342, p. 863-1993.

GUARDA, E.; KATWA, L.C.; MYERS, P.R; TYAGI, S.C; WEBER, K.T. Effects of endothelins on collagen turnover in cardiac fibroblasts. Cardiovasc. Res., v. 07, p. 2130-2134, 1993.

GUIMARÃES NETO, W.M. Musculação Anabolismo Total. $4^{\circ}$ edição. São Paulo, Phorte Editora, 2000.

HARTMAN, G.; ADDICKS, K.; DONIKE, M.; SCHANZER, W. Testosterone application influences sympathetic activity of intracardiac nerves in non-trained and trained mice. J. Auton. Nerv. Sys., v. 17, p. 85-100, 1986.

HAUPT, H.A.; ROVERE, G.D. Anabolic steroids: a review of the literature. Am. J. Sports Med., v. 12, p. 469-84, 1984.

HOLLANDER, M.; WOLFE, D.A. Nonparametric statistical methods . $1^{\circ}$ edição. Nova Iorque, John Wiley \& Sons, 1973.

JACKSON, K.; GARRISON, J.C. Renin and angiotensin. In: Hardman J.G.; Limbird, L.E. The Pharmacological Basis of Therapeutics (Goodman \& Gilman`s). New York, Mcgraw-Hill, p. 733-758, 1996. 
JALIL, J.E.; DOERING, C.W.; JANICKI, J.S.; PICK, R.; SHROFF, S.G.; WEBER, K.T. Fibrillar collagen and myocardial stiffness in the intact hypertrophied rat left ventricle. Circ. Res., v. 64, p. 1041-1050, 1989.

JORNAL DA MUSCULAÇÃo. São Paulo, Federação Paulista de Musculação, 2002.

KARHUNEN, M.K.; RAMO, M.P.; KETTUNEN, R.; HIRVONEN, L. The cardiovascular effects of reconditioning after endurance training in rats. Acta Physiol. Scand., v. 133, p. 307-314, 1988.

KENNEDY, M.C; Lawrence. Anabolic steroid abuse and cardiac death. Med. J. Aust., v. 158, p. 3646-348, 1993.

KLEINER, S.M.; CALABRESE, L.H.; FIELDER, K.M.; et al. Dietary influences on cardiovascular disease risk in anabolic steroid-using and no using bodybuilders. $\mathbf{J}$. Am. Coll. Nutr., v. 08, p. 109-119, 1989.

KOENIG, H.; GOLDSTONE, A.D.; LU, C.Y. Testosterone-mediated sexual dimorphism of the rodent heart: ventricular lyssosomes, mitochondria, and cell growth are modulated by androgens. Circ. Res., v. 50, p. 782-787, 1982. 
KOENIG, H.; FAN, C.C.; GOLDSTONE, A.D; et al. Polyamines mediate androgenic stimulation of calcium fluxes and membrane transport in rat heart myocytes. Cir.Res.,v. 64, p. 415-426, 1989.

LEGROS, T.; McDONNELL, D.; MURRY, T.; EDAVETTAL, M. et al. The effects os 17 alpha-methyltestosterone on myocardial function in vitro. Med. Sci. Sports. Exerc., v. 32, p. 897-903, 2000.

LEMONICK, M.D. A volta das drogas. Folha de São Paulo, Empresa Folha da Manhã AS, São Paulo,1999.

LENGSFELD, M.; MORANO, I; GANTEN, U., et al. Gonadectomy and hormonal replacement changes systolic blood pressure and ventricular myosin isoenzimes pattern of spontaneously hypertensive rats. Circ. Res., v. 63, p.1090-1094, 1988.

LEONETTI, G.; CUSPIDI, C. The heart and vascular changes in hypertension. J. Hypertension, v. 13, p. S29-S34, 1995.

LLEWELlyn, W. Anabolic Steroid Reference Manual - Anabolics 2000. $1^{\circ}$ edição. Estados Unidos, Anabolics.com Inc, 2000.

LUKE，L.J; FARB，A; VIRMANI，R; SAMPLE，R.H.B. Sudden cardiac death during exercise in a weight lifter using anabolic androgenic steroids: Pathologic and toxicological findings. J. Forensic Sci., v. 35, p. 1441-1447, 1990. 
MANDARIM DE LACERDA, C.A. Aspectos morfológicos do remodelamento ventricular esquerdo na cardiomiopatia hipertensiva. Arq. Bras. Cardiol., v. 65, p. 523-527, 1995.

MANDARIM DE LACERDA, C. A; PESSANHA, M.G; HAHN, M.D. Reparação Miocárdica quando em uso de baixa dosagem e longa duração de inibidor da síntese de óxido nítrico. Miofibroblastos, colágeno tipo III, fibronectina. Arq. Bras. Cardiol., v. 73, p. 87-91,1999.

MATSUBARA, B.B; ZORNOFF, L.A.M. Matriz colágena intersticial e sua relação com a expansão miocárdica no infarto agudo. Arq. Bras. Cardiol., v. 64, p. 559$563,1995$.

MCGILL, H.C; SHERIDAN, P.J. Nuclear uptake of sex steroid hormones in the cardiovascular system of baboon. Circ. Res., v. 48, p. 238-244, 1981.

MAVROMATAKI, M. Greek Mythology and Religion. $1^{\circ}$ edição. Atenas, Editora Haitalis, 1997.

MELCHERT, R.B; HERRON, T.J; WELDER, A.A. The effect of anabolicandrogenic steroids on primary myocardial cell culture. Med. Sci. Sports. Exerc., v. 24, p. 206-212, 1992. 
MELCHERT, R.B; WELDER, A.A. Cardiovascular effects of androgenic-anabolic steroids. Med. Sci. Sports. Exerc., v. 27, p. 1252-1262, 1995.

MERCK, SHARP \& DOHME. Monografia do Produto - Renitec® / Maleato de Enalapril na Hipertensão - um inibidor da enzima de conversão da angiotensina, 1992.

MEWIS, C.; SPYRIDOPOULOS, I.; KUHLKAMP, V; SEIPEL, L. Manifestation of severe coronary disease after anabolic drug abuse. Clin. Cardiol., v. 19, p. 153-155, 1996.

MICROMEDEX - Drugdex Drug Evaluations . Estados Unidos, 1974-2001.

MOOLENAR, W.H. Effects of growth factors intracellular pH regulation. Ann. Rev. Physiol., v. 48, p. 363-376, 1987.

PARCIAS, C. Complexo de Adônis embaça imagem. Jornal do Brasil, Rio de Janeiro. O Dia, 2001.

PERRY, H.M.; LITTLEPAGE, B.N.C. Misusing anabolic drugs, take a drug history from well muscled patients. Bri. Med. J., v. 305, p.1251-1242, 1992.

PESOLA, M.K. Reversibitility of the haemodynamic effects induced by anabolic steroid treatment in rats. Eur. J. Appl. Physiol., v. 58, p. 125-131, 1988. 
POPE, H.G; KATZ, D.L. Homicide and near-homicide by anabolic steroid users. J. Clin Psychiatry, v. 51, p. 28-31, 1990.

POPE Jr., H.G.; PHILliPS, K.A.; OliVARDIA, R. O Complexo de Adônis - A Obsessão Masculina pelo Corpo. $1^{\circ}$ edição. Rio de Janeiro, Editora Campus, 2000.

REVISTA ÉPOCA, 28 de setembro, Rio de Janeiro, Editora O Globo,1998.

ROBERGS, R. A.; ROBERGS, S. O. Princípios Fundamentais de Fisiologia do Exercício para Aptidão, Desempenho e Saúde. $1^{\circ}$ edição. São Paulo, Phorte Editora, 2002.

ROCKHOLD, R.W. Cardiovascular toxicity of anabolic steroids. Ann. Rev. Pharmacol. Toxicol., v. 33, p. 497-520, 1993.

SAS INSTITUTE INC. SAS/STAT Users guide, Version $6.4^{\circ}$ ed.V.2. Cary, NC. SAS Institute Inc., 1989.

SACHTLEBEN, T.R; BERG, K.E; ELIAS, B.A; et al. The effects of anabolic steroids on myocardial structure and cardiovascular fitness. Med. Sci. Sports Exerc., v. 25 , p. $1254-1245,1993$.

SCHWARZENEGER, A. Enciclopédia de Fisiculturismo e Musculação. 2ำ edição. São Paulo, Artmed Editora, 2001. 
SIEGEL, S. Estatística não paramétrica. $2^{\circ}$ edição. México, Editora Trillas, 1975.

SNOCHOWSKI, M.; SAARTOK, T.; DAHLBERG, E., et al. Androgen and glucocorticoid receptors in human skeletal muscle. J. Steroid Biochem., v. 14, p. 765-771, 1981

STATIX FOR WINDOWS 2.0 ANALYTICAL SOFTWARE. Estados Unidos, 1998

SULLIVAN, M.L.; MATINEZ, C.M; GENIS, P; GALLLAGHER, E.J. The Cardiac Toxicology of Anabolic Steroids. Progress in Cardiovascular Disease. v. 41, p. 1$15,1998$.

SUN, Y.; RATSJKA, A.; ZHOU, G.; WEBER, K.T. Angiotensin-converting enzyme and myocardial fibrosis in the rat receiving angiotensin II or aldosterone. J. Lab. Clin. Med., v. 122, p. 395-403, 1993.

SUN, Y.; WEBER, K.T. Fibrosis and myocardial ACE: possible substrate and independence from circulating angiotensin II. J. Cardiac Failure, v. 1, p. 81-89, 1994. 
SUN, Y.; RAMIRES, F.J.A.; WEBER, K.T. Fibrosis of atria and great vessels in response to angiotensin II or aldosterone infusion. Cardiovasc. Res., v. 35, p. 138$147,1997$.

SWATZ, S.L. The role prostaglandins in mediating the effects of angiotensinconverting enzyme inhibitors and other drugs. Cardiovasc. Drug Ther., v. 1, p. 3943, 1987.

TAGARAKIS,C.V.;BLOCH,W.;HARTMANN,G.;HOLLMANN,W.;et al. Anabolic steroids impair the exercise-induced growth of the cardiac capillary bed. Int. J. Sports Med., v. 21, p. 412-418, 2000).

TAYLOR, W.N. Anabolic Steroids and the Athlete. $1^{\circ}$ edição. Estados Unidos, McFarland \& Company, Inc., Publishers, 1982.

THOMPSON, P.D.; SADANIANTZ, A.; CULLINANE, E.M.; et al. Left ventricular function is not impaired in weight-lifters who use anabolic steroids. J. Am. Coll. Cardiol., v. 19, p. 278-282, 1992.

TONICA, C. Mulheres musculosas inspiram mostra em NY. O Estado de São Paulo, São Paulo, S.A. O Estado de São Paulo, 2000. 
TRIFUNOVIC, B.; NORTON, G.R.; DUFFIELD, M.J. et al. An androgenic steroid decreases left ventricular compliance in rats. Am. Physiological Society, v. 01, p. H1096- H1105, 1995

URHAUSEN, A; HOPLES, R.; KINDERMAN, W. One and two dimensional echocardiography in bodybuilders using anabolic steroids. Eur. J. Appl Physiol., v. 58, p. 633-640, 1989.

VILLARREAL, F.J.; KIM, N.N. Regulation of myocardial extra cellular matrix components by mechanical and chemical growth factors. Cardiovasc. Pathol., v. 07, p. $145-151,1998$.

WAGNER, D.; METZGER, R., PAUL, M.; et al. Androgen dependence and tissue specificity of renin messenger RNA expression in mice. J. Hypertens., v. 08, p. 45$52,1990$.

WEBER, K.T; CLARK, W.A; JANICKI, J.S; SHROFF, S.G. Physiological versus pathologic hypertrophy and the pressure overloaded myocardium. J. Cardiovasc. Pharmacol., v. 10, p. 537-550, 1987.

WEBER, K.T; JANICKI, J.S.; PICK, R; CAPASSO, J.M.; ANVERSA, P. Myocardial fibrosis and pathologic hypertrophy in the rat with renovascular hypertension. Am. J. Cardiol., v. 65, p. 1-7,1990. 
WEBER, K.T. Metabolic responses of the extracelular matrix in tissue repair. Ann. Med., v. 29, p. 333-338, 1997.

WEICKER, H; HAGELE, H; REPP, B; KOLB, J. Influence of training and anabolic steroids on the LDH isozyme pattern of skeletal and heart muscle fibers of guinea pigs. Int. J. Sports Med., v. 3, p. 90-96, 1982.

WELDER, A.A; ROBERSTSON, W.; FUGATE, R.D; MELCHERT, R.B. Anabolicandrogenic steroid-induced toxicity in primary neonatal rat myocardial cell cultures. Toxicol. Appl. Pharmacol., v. 133, p. 328-342, 1995.

WILDE, M. I.; BRYSON, H.M.; GOA, K.L. Enalapril - A review of quality of life and pharmacoeconomic aspects of its use in heart failure and milt to moderate hypertens ion. Pharmac. Drug Evaluation, v. 06, p. 155-182, 1994.

WILSON, J.D. Androgen abuse by athletes. Endocr. Rev., v. 09, p. 181-199, 1988.

WOLF, G.; HABERSTOUG, U; NEILSON, E.G. Angiotensin II stimulates the proliferation and biosyntheses of type I collagen in cultured murine mesangial cells. Am. J. Pathol., v. 140, p. 95-107, 1992.

WOODIWISS, A.J.TRIFUNOVIC, B.; PHILIPPIDES, M.; NORTON, G.R. Effects of an androgenic steroid on exercise-induced cardiac remodeling in rats.J. Appl. Physiol., v. 88, p. 409-415, 2000. 
XU, S; DENTON, C.P; HOLMER, A.; DASHWOOD, M.R; ABRAHAM, D.J; BLACK, C.M. Endothelins: effect on matrix biosynthesis and proliferation in normal and scleroderma fibroblasts. Cardiovasc. Pharmacol, v. 31, p. S360-S363, 1998.

YU-YAHIRO, J.A.; MICHAEL, R.H.; NASRALLAH, D.V.; SCHOFIELD, B. Morphologic and histologic abnormalities in female and male rats treated with anabolic steroids. Am. Journal of Sports Medicine, v. 17, p. 686-689, 1989.

ZAUGG, M.; JAMALI, N.Z.; LUCCHINETTI, E; XU, W.; et al. Anabolicandrogenic steroids induce apoptotic cell death in adult rat ventricular myocytes. J.

Cell Physiol., v. 187, p. 90-95, 2002. 